\title{
Recent advances in structural fibre-reinforced concrete focused on polyolefin-based macro-synthetic fibres
}

\author{
M.G. Alberti ${ }^{\mathrm{a}}$, A. Enfedaque ${ }^{\mathrm{a}}$, J.C. Gálvez $₫$, A. Picazo ${ }^{\mathrm{b}}$ \\ a. Department of Construction. School of Civil Engineering \\ Universidad Politécnica de Madrid, (Madrid, Spain) \\ b. Department of Building Technology. School of Building. Universidad Politécnica de Madrid, (Madrid, Spain) \\ $\varangle$ : jaime.galvez@upm.es
}

\author{
Received 22 November 2018 \\ Accepted 17 June 2019 \\ Available on line 18 February 2020
}

\begin{abstract}
Fibre-reinforced concrete (FRC) allows reduction in, or substitution of, steel-bars to reinforce concrete and led to the commonly named structural FRC, with steel fibres being the most widespread. Macro-polymer fibres are an alternative to steel fibres, being the main benefits: chemical stability and lower weight for analogous residual strengths of polyolefin-fibre-reinforced concrete (PFRC). Furthermore, polyolefin fibres offer additional advantages such as safe-handling, low pump-wear, light weight in transport and storage, and an absence of corrosion. Other studies have also revealed environmental benefits. After 30 years of research and practice, there remains a need to review the opportunities that such a type of fibre may provide for structural FRC. This study seeks to show the advances and future challenges of use of these polyolefin fibres and summarise the main properties obtained in both fresh and hardened states of PFRC, focussing on the residual strengths obtained from flexural tensile tests.
\end{abstract}

KEYWORDS: Concrete; Fibre reinforcement; Mechanical properties; Tensile strength; Durability; Polyolefin fibres.

Citation/Citar como: Alberti, M.G.; Enfedaque, A.; Gálvez, J.C., Picazo, A. (2020) Recent advances in structural fibrereinforced concrete focused on polyolefin-based macro-synthetic fibres. Mater. Construcc. 70 [337], e206 https://doi. org/10.3989/mc.2020.12418

RESUMEN: Avances recientes en hormigón estructural reforzado con fibras, con especial atención a macro fibras sintéticas de poliolefina. El hormigón reforzado con fibras (HRF) permite la reducción parcial o total de barras de acero en el hormigón armado, acuñándose término HRF estructural, siendo las fibras de acero las más usadas. Las macro-fibras poliméricas son una alternativa a las de acero, aportando estabilidad química y menor peso para resistencias residuales iguales. Además, las fibras de poliolefina ofrecen beneficios adicionales tales como mayor seguridad de trabajo, menor desgaste de equipos de bombeo, menor peso en el transporte y almacenamiento, y ausencia de corrosión. Otros estudios también han revelado beneficios medio-ambientales. Después de 30 años de investigación y práctica, sigue siendo necesario analizar las oportunidades que estas fibras de poliolefina pueden proporcionar al HRF estructural. Este estudio muestra los avances y posibilidades del uso de estas fibras y resume las principales propiedades obtenidas tanto en estado fresco como endurecido, centrándose en la resistencia residual obtenida en los ensayos de tracción por flexión.

Palabras clave: Hormigón; Refuerzo de fibras; Propiedades mecánicas; Resistencia a la tracción; Durabilidad; Fibras de poliolefina.

ORCID ID: M.G. Alberti (http://orcid.org/0000-0002-7276-8030); A. Enfedaque (http://orcid.org/0000-0002-5659-7358); J.C. Gálvez (http://orcid.org/0000-0001-9106-2917); A. Picazo (http://orcid.org/0000-0001-8496-8008)

Copyright: (C) 2020 CSIC. This is an open-access article distributed under the terms of the Creative Commons Attribution 4.0 International (CC BY 4.0) License. 


\section{INTRODUCTION}

Over the years, concrete has been conventionally reinforced with steel-bars placed in the tensile zone of structural members such as, among others, beams and slabs. Such a combination has been shown as the most successful composite material used in construction in modern times. The section forces may be equilibrated in structural members by utilising the best performance of each material: while compression stresses are borne by concrete, tensile stresses are borne by the steel bars. Nonetheless, the development of microcracks and macro-cracks in reinforced concrete (RC) by the local use of reinforcing bars should not be avoided (1). Such cracking may be limited if continuous reinforcement, instead of a local one, is used.

The idea of reinforcing brittle materials subjected to tensile stresses with a continuous reinforcement dates from centuries ago when straw was used to strengthen bricks or horsehair was done so to reinforce plaster, with this intuitive technique being used by the Egyptians and Mesopotamians. The Exodus is probably the oldest manuscript where this method is cited and there exist examples of constructions like the ziggurats of Aqar Quf where such a solution was applied. In more recent times, in 1874 in the United States, Bérard patented what was named Improvement in artificial stone in which he proposed adding waste iron to small pieces of concrete. Development of such an idea emerged at the beginning of the 20th century when asbestos fibres were used to strengthen cement mortars. While use of asbestos fibres was forbidden later due to environmental and health factors, such a combination may be considered to be the first application of modern fibre-reinforced concrete (FRC).

From 1912 to 1927, in France, Germany and the United States there were several patent applications that involved cement mixes reinforced with glass or steel fibres. In the 1950s and 1960s, the modern concept of disperse reinforcement of concrete was proposed by adding steel fibres to the fresh mix. Such a concept was developed from the first studies about composite materials with a cementitious matrix. Notable ones were the works of Romualdi with Batson and Mandel in 1963 and 1964 (2, 3), which had a significant impact on the construction industry and led to new research. Although the wide range of benefits offered by FRC had not been explored, at that time application permitted use of steel fibrereinforced concrete (SFRC) in pavements which required a certain degree of resistance to abrasion.

Given that RC is the par excellence option for construction structures, it is of little surprise (and considering the experience available in the FRC field) that researchers have sought to improve the inherent brittle nature of concrete not only locally as in RC but also in the overall concrete piece. This approach was carried out by adding fibres with high-tensile strengths randomly distributed in the bulk concrete matrix. The properties that the fibres confer to concrete enable, if certain requirements are satisfied, a partial or even total substitution of steel-bars. Should this occur, the addition of fibres would not only reduce the cost of the structure but also provide other improved properties. Steel fibres have conventionally been those most used for such applications.

The production of SFRC requires use of selected raw materials, chemical admixtures and special operational technologies, all of which inevitably increase costs. For this reason, SFRC may be profitable only when special structural requirements are needed, such as in pavements and tunnelling. However, as structural design has become increasingly demanding, the popularity of SFRC has risen in building and civil construction. Consequently, some constitutive models, design approaches and tests have been performed (4-9) to meet such requests.

While the remarkable mechanical performance of steel combined with concrete is recognised, such a combination has serious drawbacks regarding durability. Steel is not only highly corrodible in nature, but also costly to purchase, store and handle. Durability issues regarding SFRC have concerned engineers and construction companies, with (to address such challenges) a variety of fibres being developed with several purposes employed in everyday practice (10). Fibres were made from constituent materials such as glass, carbon or synthetic polymers in various shapes and surface textures that sought to improve certain properties in FRC. Common applications of FRC include overlays in bridge decks, thin shell elements, blast-resisting and seismic and structures and many others, with each being a versatile and practical technology with a wide range of uses $(11,12)$.

Some of the applications of the aforementioned fibres seek to avoid or at least reduce concrete cracking. Such a phenomenon is a consequence of stresses that appear due to external forces or other deformation effects like shrinkage. Hence, reinforcement of the fibres depends on the cause of the cracking process considered. For such a reason there exist several fibre types manufactured with distinct constituent materials, shapes and sizes which offer a tailor-made solution in order to prevent cracking propagation. The Spanish Structural Concrete Code EHE-08 (9) considers three typologies of fibres: steel, synthetic and glass. The American Concrete Institute (4) adds a fourth group of natural fibres. Regarding the European Standards, in 2006 EN $14889(13,14)$ and EN 14845 (15) were approved to include in both of them fibres for concrete. Such standards incorporated only steel and polymer fibres. Nonetheless, the springboard for the increase in the use of fibres in concrete for structural applications (16) was the publication of the fib Model Code 2010 (5) which included specific sections that dealt with structural design with FRC. 
Recently, the efforts of the plastic industry have enabled production of a new generation of polyolefin-based synthetic macro-fibres that are inert in an alkaline environment and provide structural capacities able to substitute conventional concrete steel reinforcement (17). Polyolefin fibres are produced from homo-polymeric resin into a mono-filament form (18). Such fibres offer good tensile properties, resistance to abrasion, and excellent resistance in chemically aggressive environments which, added to a low cost, make them an alternative to steel solutions when meshes or fibres are used (19, 20). Polyolefin fibre-reinforced concrete (PFRC) has considerable residual tensile strength $(21,22)$ and a lower weight in comparison with steel fibres. Researchers and the construction industry have made significant progress in applying plastic fibres to reinforcing concrete (23-25). Mainly due to the lower cost of the material and its production process (together with a lack of corrosion when subjected to hazardous environments), the use of such a type of fibres has become appealing.

Published research has shown that fracture behaviour of PFRC obtains structural capacities with lower dosages than steel fibres in terms of weight (26-28).Furthermore, test results have revealed a limited degree of scattering even with notable intentional variations of the concrete characteristics and production conditions $(29,30)$. In addition to this, the fresh-state and hardened properties of PFRC were suitable for structural uses, with the presence of fibres not hindering the results of permeability tests (depth of water penetration under pressure). This means that the quality of the concrete in terms of durability was unaffected (31). Likewise, applications and research have produced this type of concrete with reliability and obtained results that exceed the requirements of the regulations for real applications $(17,32)$.

Another characteristic of PFRC that should not be neglected is that it provides multiple sustainability benefits if compared with the common practice of using steel a reinforcing mesh or steel fibres (19). Such benefits have been measured in new research where both the use and end-of-life cycles of PFRC and the aforementioned common practice have been examined (33). In terms of the weight needed to reach similar strengths, the lower dosages of fibres reduce transport costs and, consequently, the carbon footprint of the lifecycle of the material. Derived from the production methods, significant decreases of carbon emissions, when compared with steel production, may also be found in the literature (34). Regarding production benefits, plastic fibres can be directly mixed with concrete without clustering problems and with a reduced impact on workability. Even by using ready-mix trucks, published research has shown that in comparison with steel fibres the loss of fibres is somewhat limited (35).
In addition, the handling of this type of fibres is safer and lighter and saves time in operations such as preparation and placing of the wire mesh. These aspects permit continuous production of concrete that sets with a consequent reduction in labour costs $(23,32,36)$. Hence, PFRC has become an appealing solution that provides certain additional advantages if the whole lifecycle is considered (33).

This article seeks to justify the need for a study that includes the relevant features when dealing with PFRC. Consequently, the aim is to examine the recent advances made in the use of macro-polymer fibres in concrete with structural objectives. This will provide an overview of the opportunities offered by such fibres and condense the technical know-how acquired in the last years in both dayto-day practice and research. It could also help structural designers in using this composite material in a safer way.

\section{OVERVIEW OF POLYOLEFIN FIBRES}

Polymer science has provided advances in the chemical composition and mechanical properties of polyolefins. This has led to an increment in common applications and has become the fastest growing polymer family, given that they are produced with lower costs than the plastics and materials that they substitute (37). Some polyolefins are widely known such as polyethylene (PE) and polypropylene (PP). However, it should be mentioned that in the case of fibres for reinforcing concrete, fibres manufactured using PE or PP are mostly produced in form of micro-fibres. Therefore, a direct comparison between the properties that PP or PE fibres confer to concrete with the improvements that polyolefin fibres introduce in FRC would be biased. The commercial advantages and disadvantages associated with polyolefin fibres are shown in Table 1 which have been extracted from ref. (38). It should be noted that not all the properties shown can be associated with the use of polyolefin fibres in reinforced concrete. As a summary, polyolefin fibres have good tensile properties, good abrasion resistance and excellent resistance to chemicals.

Focusing on polyolefin fibres manufactured to reinforce concrete elements, recent developments have allowed the plastic industry to obtain polyolefin-based synthetic macro-fibres with improved mechanical properties. This type of fibres has become an alternative to steel fibres, as research has shown in various applied studies $(23,32)$ and research publications $(22,31,39-40)$. As the importance of the material durability has emerged, some additional properties of polyolefin fibres have given rise to certain advantages in the construction field if compared with steel fibres. In such a sense, the potentially corrodible nature of steel fibres has generated an interest in fibres that 
TABLE 1. Commercial advantages and disadvantages associated with use polyolefin fibres (38).

\begin{tabular}{ll}
\hline Advantages & Disadvantages \\
\hline Low density $\left(0.90-0.96 \mathrm{~g} / \mathrm{cm}^{3}\right)$ & Low melting point $\left(120-125^{\circ} \mathrm{C}\right.$ for PE, $160-165{ }^{\circ} \mathrm{C}$ for PP $)$ \\
Good tensile properties & Prone to photolytic degradation \\
Good resistance to abrasion & Inferior shrink resistance above $100^{\circ} \mathrm{C}$ \\
Excellent resistance to chemicals & Poor dyeability \\
Excellent resistance to mildew, micro-organisms and insects & High flammability \\
Negligible moisture regain & Inferior resilience \\
Remarkable wicking action & Significant degree of creep \\
High insulation & \\
Avoidance of dermatological problems & \\
\hline
\end{tabular}

TABLE 2. Typical properties and outlook of polyolefin fibres for concrete

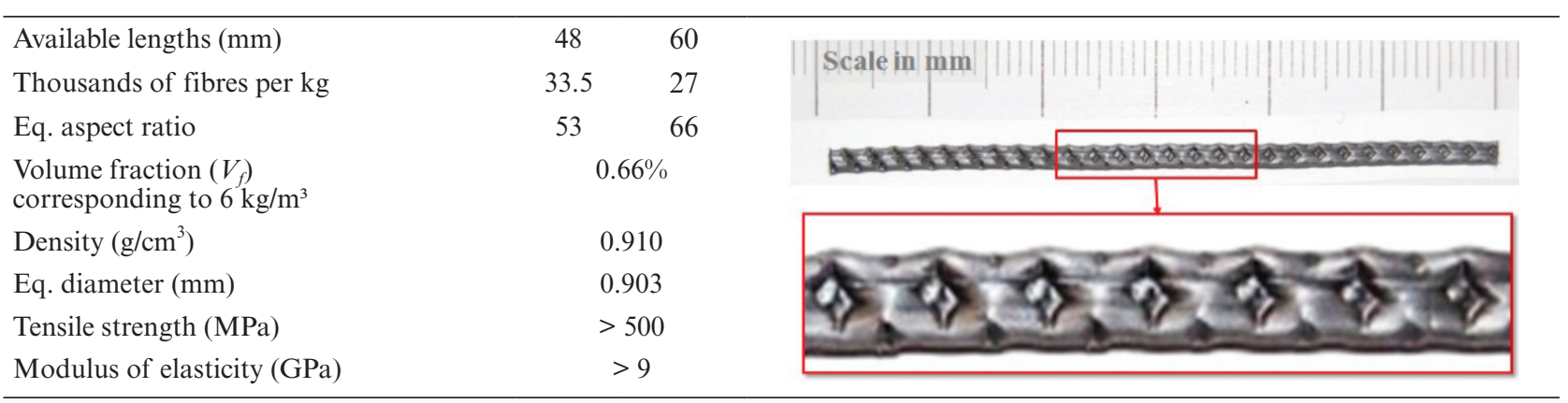

both provide chemical stability and increase the mechanical performance of concrete. Recently, the plastic industry has examined the aforementioned disadvantages of steel fibres, producing in response a new generation of polyolefin-based synthetic macro-fibres. Polyolefin fibres which have good tensile properties, resistance to abrasion and excellent resistance to chemical attacks have emerged as an alternative to the use of a steel-reinforcing mesh or steel fibres (41). Table 2 shows the main properties of commercial polyolefin fibres designed for concrete applications.

\section{CLASSIFICATION OF FIBRES ACCORDING TO THE EUROPEAN STANDARDS}

The most relevant fibres for reinforcing concrete are steel and polymer. The European Standard 14889 comprises two parts: the first one examines steel fibres; (13) and the second one polymer fibres (14). Such a standard is focussed on standardised testing methods and defines the possible geometric shapes, physical parameters and mechanical properties of the fibres. The polymer fibres are divided into two groups: non-structural micro-fibres and structural macro-fibres. Figure 1 shows the scheme of classification. EN 14889 requires that manufacturer declares the volume of fibres $\left(\mathrm{kg} / \mathrm{m}^{3}\right)$ which provides a flexural post-cracking residual strength of $1.5 \mathrm{MPa}$ in a value of crack mouth opening displacement (CMOD) of $0.5 \mathrm{~mm}$, with a minimum $1 \mathrm{MPa}$ of residual strength for CMOD of $3.5 \mathrm{~mm}$ by using a reference concrete (see EN 14845 (15)). These values should be obtained in a test performed as stated in EN 14651 (42). The Model Code (5) should define the same requirements as a percentage of the maximum strength obtained in such test. This has been justified with the purpose of avoiding brittleness (16).

\section{THE BEGINNING OF USE OF POLYOLEFIN FIBRES TO REINFORCE CONCRETE}

One of the reasons for the good performance of polyolefin fibres is the good bond among them and, due to the their rough surface of the former, the concrete matrix. Such roughening generates a mechanical interlock that opposes the extraction forces after cracks appear. Some published studies have attempted to improve the materials and surface treatments of the fibres, seeking to limit the bundle effect and enhance the pull-out resistance by using a bond improver $(44,45)$.

The aforementioned properties enabled the use of polyolefin fibres used in barriers, pavements and for 


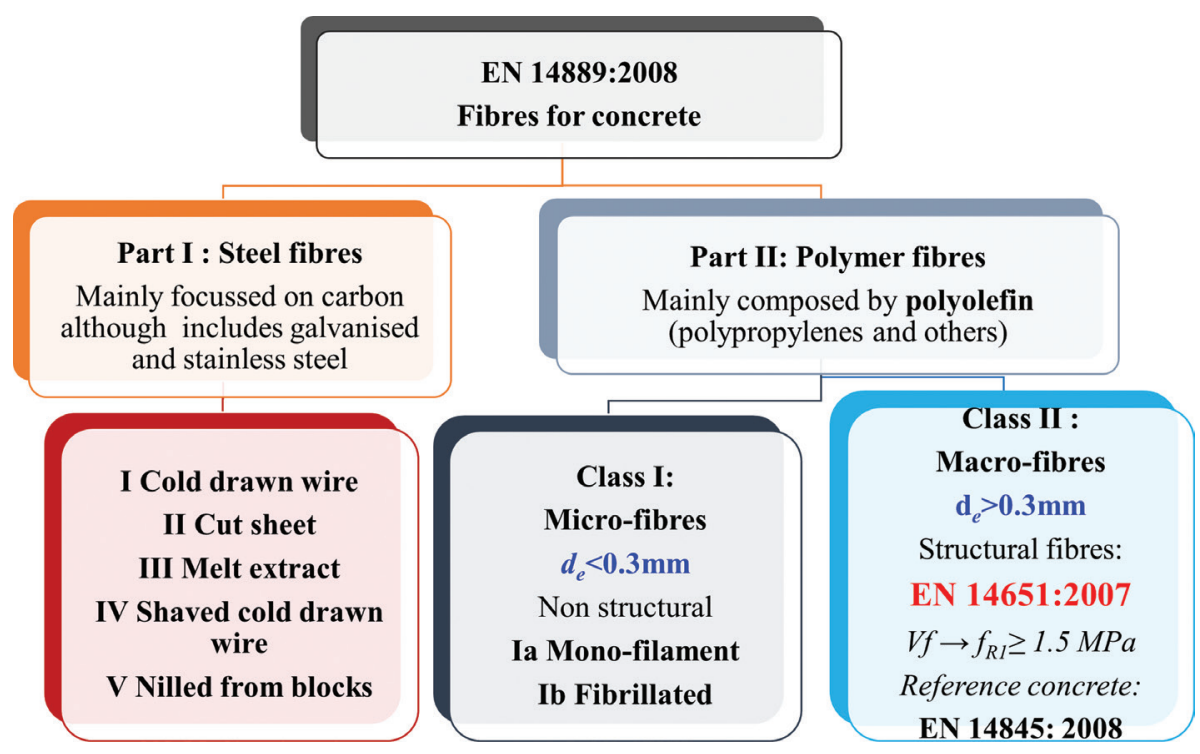

FIGURE 1. Fibre classification following EN-14889. Adapted from: (43).

a bridge deck overlay performed by Ramakrishnan in 1990. In such applications, the amount of fibres reached $14.8 \mathrm{~kg} / \mathrm{m}^{3}(1.66 \%$ volumetric fraction), reporting not only a considerable increase of toughness and ductility but also a significant increase in impact and fatigue resistance. The authors showed that such applications were constructed with noncorrosive, non-hazardous, non-metallic and nonmagnetic fibres. In addition, the finishing surface protrusions were non-hazardous (10).

In a later study, Ramakrishnan and Sivakumar (46) studied PFRC under cyclic loading. In 1998, Mindess and Wang (47) studied polyolefin FRC under impact loading. Both studies obtained satisfactory results. In addition, Yan, Jenkins and Pendleton used polyolefin fibres with a smooth surface (48) and verified that those of a greater diameter and those with a crimped geometry provided higher damping ratios.

In the last 15 years more advances have been made. Trottier and Mahoney (49) performed a comparative analysis of slabs-on-ground behaviour with four types of reinforcement. They concluded that in fresh state the concrete was remarkably workable (they did not identify significant variations on compressive strength in hardened state). Cengiz and Turangli (50) compared steel mesh with both steel fibre-reinforced shotcrete (SFRS) and macro-synthetic fibre-reinforced shotcrete (PFRS) in panel tests. The authors confirmed that there was a remarkable reduction of loss of fibres due to rebound when polyolefin fibres being used. Recently, Pujadas et al. (17) concluded that although SFRC was the main source of the existing design codes and constitutive models, it was possible to fit the PFRC behaviour to them. Concerning durability, in 2004 Bernard (51) evaluated the durability performance of macro-synthetic fibres on precracked specimens. Durability of PFRS was found to be excellent in both inland and coastal environments.

\section{MIX PROPORTIONING, FRESH STATE AND FABRICATION OF FRC}

Macro-fibre volumes are currently used in practice and range from $0.3 \%$ to $1.5 \%$ (in volume). The procedure for mix proportioning may in essence be the same as that used for plain concrete (31). The reduction of concrete workability that the presence of fibres may cause could be compensated by including slight variations of the aggregate proportioning, increasing the amount of fine fractions or even modifying the amount of admixtures. FRC may be manufactured by studying the best mixing sequence to ensure a good dispersion of fibres, avoiding segregations and balling. In the case of polyolefin macro-fibres, no risk of balling has been found in the literature (31). Concerning the type and content of cement, there are not either limitations or special recommendations. Concerning the aggregate size, not only an increase of fines/ total aggregates is typically adequate but also a limited maximum aggregate size $\left(D_{a g, \max }\right)$. This limitation of $D_{a g, \max }$ influences the effectiveness of reinforcement in hardened state because it determines fibre distribution. In addition, such a limitation enhances FRC workability. However, it should be noted that most of these conclusions were extracted for rigid fibres. Such effects could not appear in the same manner for bendable fibres, as depicted in Figure 2 from ref. (31). Table 3, which 
$60 \mathrm{~mm}$ long macro-synthetic fibres

$5 \mathrm{~mm}$

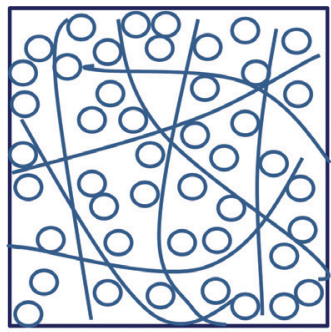

$10 \mathrm{~mm}$

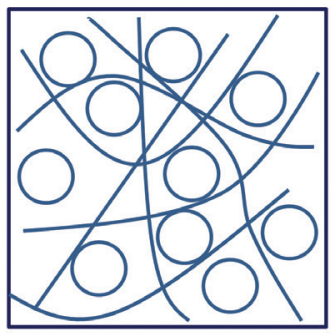

$60 \mathrm{~mm}$
$20 \mathrm{~mm}$

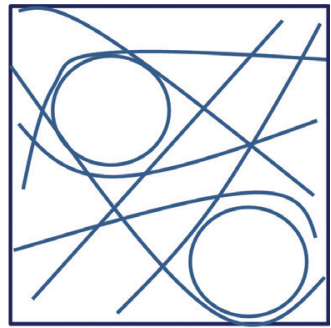

FIGURE 2. Effect of the aggregate size on the fibre distribution (31).

TABLE 3. Comparisons of the bending stiffness and properties of steel fibres (SF) and polyolefin fibres (PF) (52).

\begin{tabular}{lcccc}
\hline & Inertia $\left(\mathbf{m m}^{4}\right)$ & $\boldsymbol{E}(\mathbf{G P a})$ & Stiffness $\left.\boldsymbol{E} \boldsymbol{I}(\mathbf{N m m})^{2}\right)$ & Bending stiffness $(\boldsymbol{E} \boldsymbol{I} \boldsymbol{L})^{*}$ \\
\hline PF & 0.0168 & 10 & 168 & 2.80 \\
SF & 0.0045 & 210 & 943 & 26.95 \\
\hline
\end{tabular}

*In the case of $\mathrm{PF}, \mathrm{L}=48 \mathrm{~mm}$; for $\mathrm{SF}, \mathrm{L}=35 \mathrm{~mm}$

has been extracted from ref. (52), shows difference in stiffness.

The presence of a high content of fibre and coarse aggregates can decrease FRC compactibility to a significant extent. When fibres are added to a vibrated conventional concrete (VCC), a drop of $9 \mathrm{~cm}$ in the Abrams cone test is recommended (9). Although it is true that as the amount of fibres grows the viscosity of the PFRC increases, it should not be overlooked that the influence of the fibres is reduced when compared with the effect that steel fibres produce. In such a sense, it has been found that with an increment of around 15\% of amount of superplasticiser added to the mix, it is possible to maintain similar values of the slump even when adding $10 \mathrm{~kg} / \mathrm{m}^{3}$ of polyolefin fibres $(27,41)$.

In the case of self-compacting concrete (SCC), the diameter of the patty obtained in the slump flow test decreases with the addition of fibres. Consequently, fibres are detrimental to self-compactibility. The design criteria proposed in references $(21,26,30)$ included a target slump flow (53) diameter of $700 \mathrm{~mm}$ before fibres are added. However, the flexible nature of polyolefin fibres reduces the deleterious effect of fibres in concrete fresh state significantly. In the case of a SCC, the fresh-state properties of the concrete are frequently assessed through conducting tests such as the slump flow test, the L-box test and the V-funnel test (116, 117). Figure 3 shows that the influence of polyolefin fibres in SCC, in both the slump test and the V-funnel test, is limited (54). This phenomenon underlines the versatile nature of polyolefin fibres if compared with rigid steel fibres. In addition, even in the case of a $10 \mathrm{~kg} / \mathrm{m}^{3}$ addition of fibres, no hint of balling was noticed. Furthermore, there is evidence that concrete with polyolefin fibres discharged from ready-mix trucks maintains a regular distribution of fibres throughout the concrete mass (35). Moreover, the obtaining of the desired fresh properties in the slump flow test (53) and V-funnel test (54) are closely related and may also be assessed by use of rheological measurements.

The placing stage of SCC improves the positioning of fibres in the pouring direction. However, external vibration has shown a tendency for the fibres to be aligned perpendicular to the direction of vibration for polyolefin fibres (27). In order to avoid some of the differences that such manufacturing stages could produce, test recommendations EN 14651:2007+A1 (42) and RILEM TC 162-TDF (6) have established a procedure for casting the specimens and filling the moulds. In the case of a VCC, the mould should be topped up and levelled off while being compacted by external vibration. Furthermore, in the case of SCC the standards state that the mould should be filled in a single pour and levelled off without any compaction. Figure 4 shows both procedures. In the case of the combination of SCC and PF, published research has shown that pouring concrete into the moulds from the centre produces an overestimate of the residual strengths. Figure 5 shows the map of the average orientation factor along the beams from the references $(26,29-31)$.

It should not be overlooked that the fresh-state evaluation, compaction and finishing stages affect 

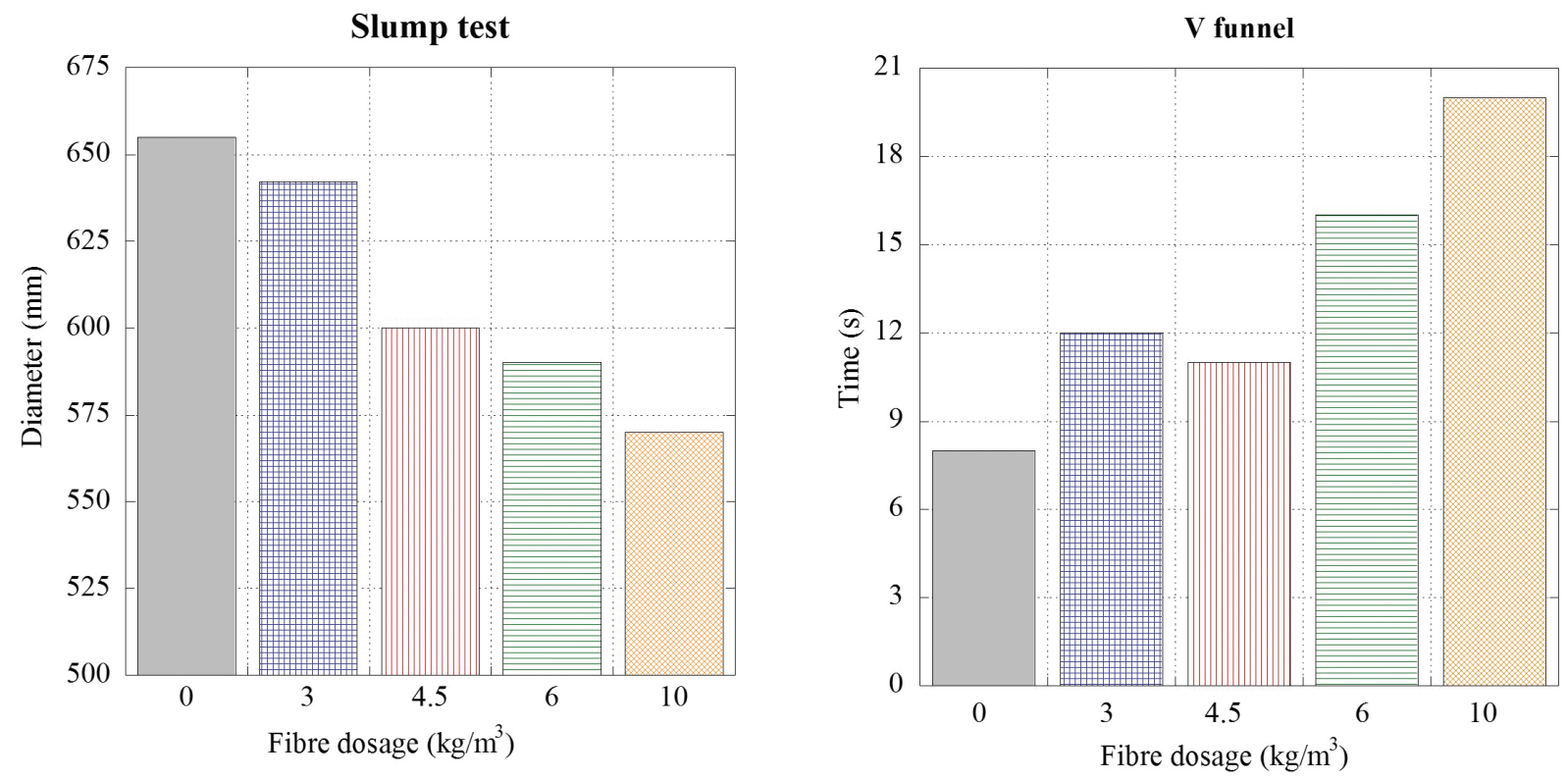

FIgURE 3. Slump-flow and V-funnel test results in a PFRC-SCC. Adapted from: (31).

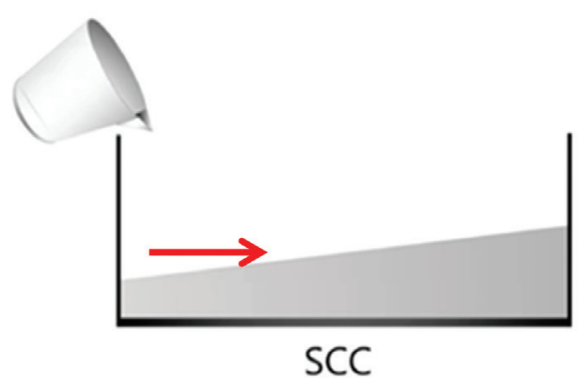

(a)

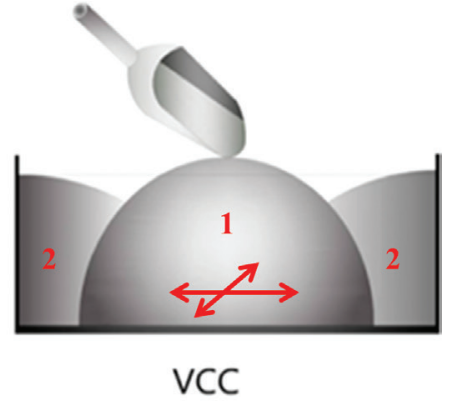

(b)

FIgURE 4. Filling methods for FRC: (a) flow method for SCC; (b) RILEM and EN-14651 Vibrated Concrete (31).
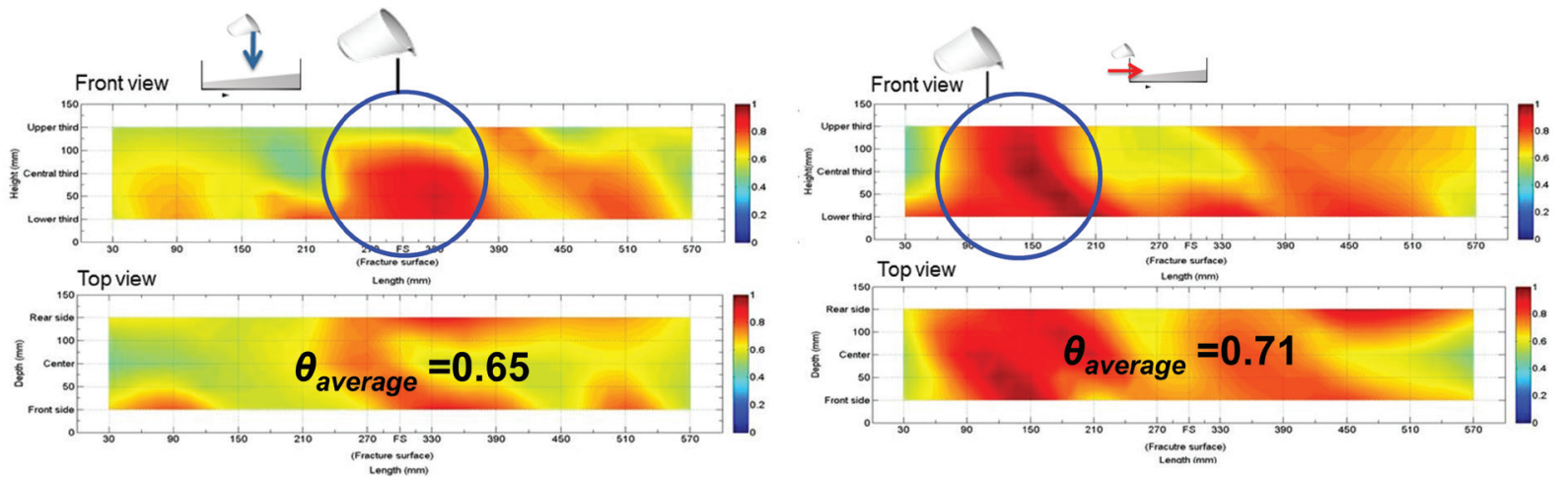

FIGURE 5. Variation of the orientation factor in standard specimens by filling the moulds with PFRC self-compacting concrete from: (a) the centre; (b) one side. Adapted from: (26).

the positioning of the fibres and thus the scatter and performance in hardened state. Figure 6 shows the production methods of both types of concrete. In all cases, once demoulded (as in the case of a conventional concrete) the elements should be properly cured. In the case of laboratory specimens, this should involve curing at $20^{\circ} \mathrm{C}$ at a relative humidity above $95 \%$ until the age of testing. 


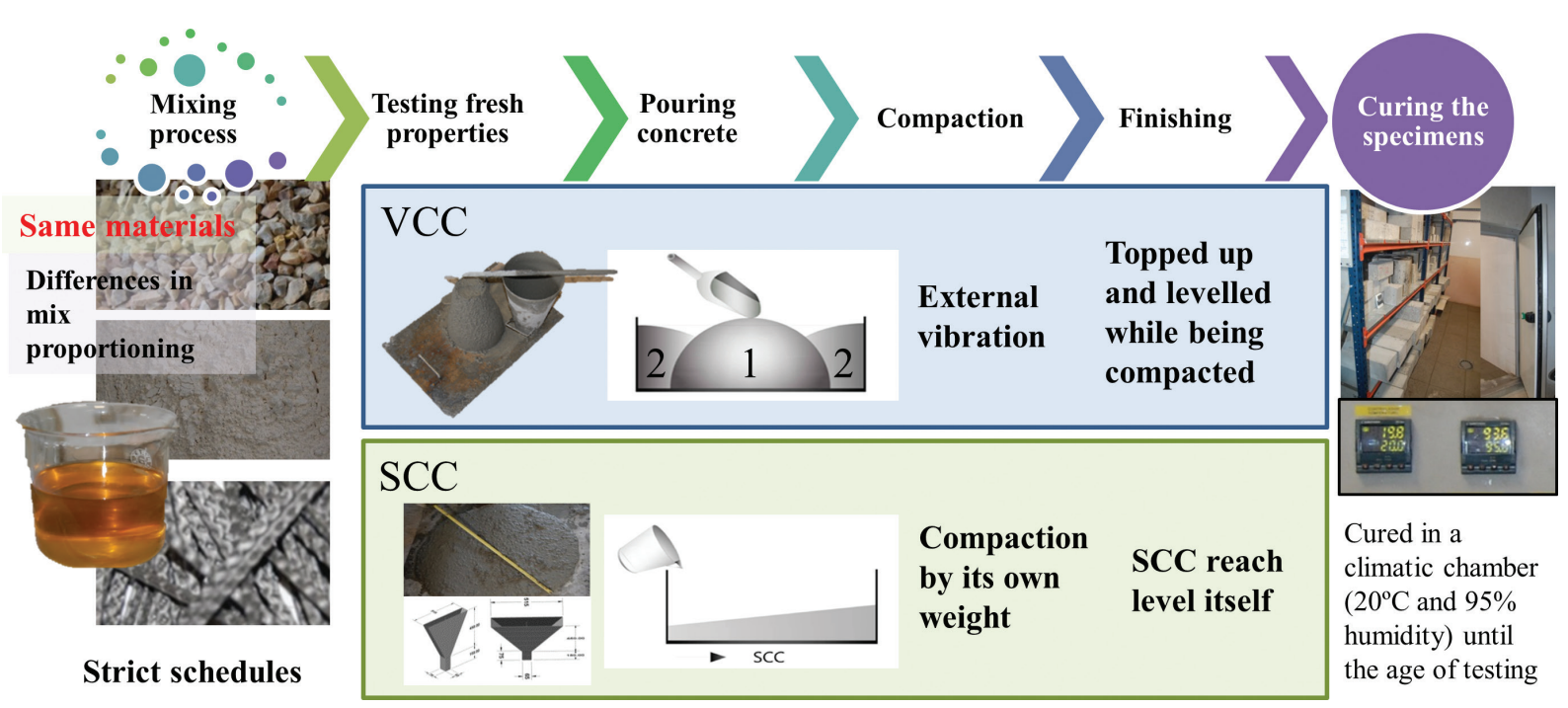

FIGURE 6. Typical concrete production procedures for VCC and SCC (31).

\section{EFFECT OF POLYOLEFIN FIBRES ON THE MECHANICAL PROPERTIES}

The influence of the fibres on the mechanical properties varies depending on the type and shapes of the fibres. This subsection is focussed on the changes that fibres provide to the main mechanical properties of concrete. Special attention should be paid to the residual post-cracking tensile strength, given that it is the keystone in the use of structural fibres (31). Consequently, a section focussed on examination of fracture behaviour under tensile or flexural stresses is presented.

In addition to being used to characterise concrete, compressive strength provides essential information for structural design in PFRC. The test is performed in a similar way to that of plain concrete (56) and with the usual amounts of fibres used (the strength results are affected in an insignificant manner). Nevertheless, failure is less brittle, as may be deduced from a typical curve of compressive strength and axial strain (57). In a conventional concrete, strength is not significantly affected when regular amounts of polyolefin fibres are added. Nevertheless, failure is usually less brittle due to the enhancement of the ductility and toughness provided by the fibres. Even a reduced amount of fibres produces remarkable changes in failure mode, giving rise to scarcely any loss of mass of the specimen. Nonetheless, there would seem to be a threshold of volume fraction from which compressive strength may be reduced. This may happen due to worse workability and compaction which cause heterogeneities in the concrete bulk, thus reducing compressive strength. Some existing fracture mechanics models assume that a second mode of failure takes place within the longitudinal tensile cracks which form a shear band as the adjoining parts begin to slide (58). The mechanical explanation of such a change in failure mode lies in a reduction of lateral deformations above stress values greater than $75 \%$ of the compressive strength. Such a change prevents the typical shear bands of plain concrete failure mode from emerging, avoiding the explosive failure of the plain material without fibres.

In order to assess tensile strength, splitting tests (also named Brazilian tests) may be carried out. Such tests involve an indirect method for applying near-constant tensile stress in the central part of the vertical diameter (59) of the specimen. Here the existence of a post-cracking branch of the curve, which does not appear in the case of plain concrete, is itself a sign of the deformation capacity of FRC. In such a sense, fibres provide tensile strength to the composite material due to a capacity to transfer stress through the crack. Consequently, this test method may be suitable for a quality-control test (31), though only when the load at the first crack corresponding to peak load for plain concrete is analysed. This type of test is unsuitable for assessing the residual strength of the materials provided by the fibres due to second-order effects that do not allow accurate residual strength values to be obtained, as shown in Figure 7. Figure 8 shows that it could be the influence of the fibre volume could be considered negligible if the amount of fibres remains within the regular ranges.

Concerning the modulus of elasticity $(E)$ of the composite material, although theoretically its value should be related to the proportions of concrete and fibres, some other parameters should be considered such as fibre orientation and length. Even in such a case, the influence of the fibres on the modulus of elasticity obtained by EN 12390-13 (60) is unclear, as Figure 8 shows. In some cases, even in the case of adding fibres with a higher modulus of elasticity 

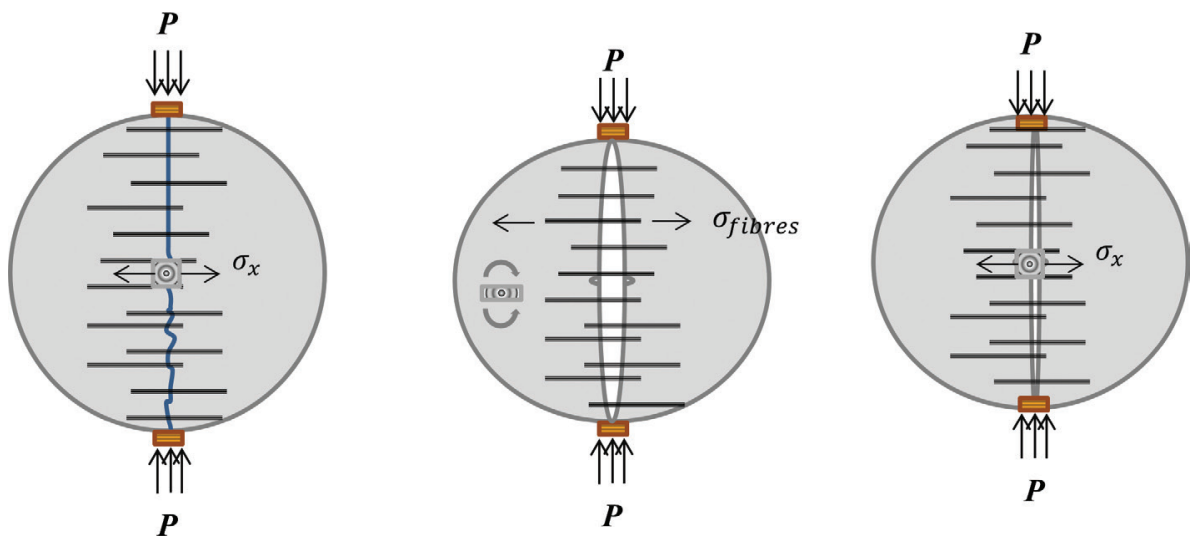

FIGURE 7. Second order effects during indirect tensile strength tests with FRC (31).

\section{Relative mechanical properties}

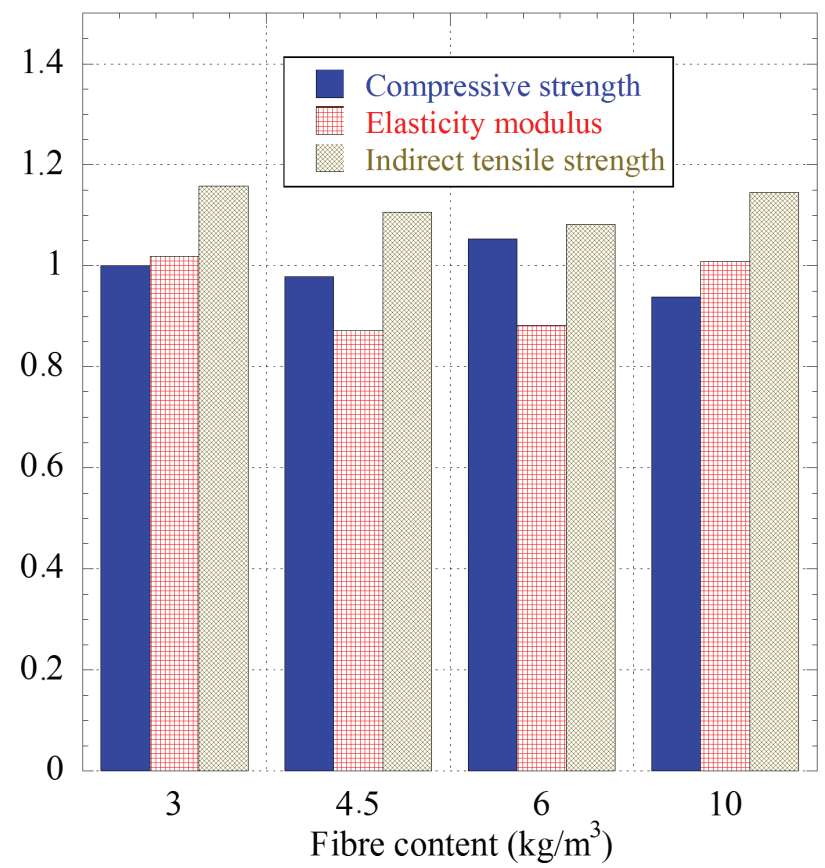

FIGURE 8. Mechanical properties of PFRC with respect to plain concrete which is taken as the unity values. Adapted from: $(31,41)$

than the matrix, a lower value of the composite material has been obtained $(61,62)$.

Several studies have been conducted regarding the creep evolution of concrete reinforced with synthetic macro-fibres. Serna et al. (108) analysed the residual bending strength of prismatic specimens of concrete reinforced with $0.5 \%$ of synthetic macrofibres which had been previously pre-loaded up to a crack opening of $0.5 \mathrm{~mm}$ and placed in several environments (laboratory, air at $45^{\circ} \mathrm{C}$ and seawater at $45^{\circ} \mathrm{C}$ ). The experimental campaign found that after 90 days of exposure the residual load borne capacity had not been modified. Another approach was adopted by (109) where a comparison between the behaviour of nylon and polypropylene fibre-reinforced concrete was carried out. Beams were loaded at an intermediate stress state, looking for creep failure and determining the maximum flexural stress sustainable indefinitely. Results showed that the sustainable stress in that case was much lower than the post-cracking strength. Other authors assessed the evolution of post-cracking flexural creep in beams manufactured with synthetic fibres which had been loaded at a $60 \%$ of the residual strength during one year (110). Such authors found that there was a continuous increase of the deformation. Such behaviour was confirmed in some other studies where macrosynthetic FRC loaded at 50\% of the static residual capacity increased its deformation as time passed (111). As can be concluded neither there is homogeneity among all the results nor a standard method for testing synthetic FRC under creep situations.

Regarding the behaviour of FRC subjected to flexural fatigue, most of the studies performed have dealt with steel FRC and there are hardly any analysis concerning synthetic FRC. In the case of the SFRC an increment of the fibre content increases significantly the cumulative energy absorption (112). Other authors developed $\mathrm{S}-\mathrm{N}-\mathrm{P}_{\mathrm{f}}$ curves from the fatigue test data to relate the stress level $\mathrm{S}$, fatigue life $\mathrm{N}$, and probability of failure $\mathrm{P}_{\mathrm{f}}(113)$

\section{PULL-OUT BEHAVIOUR}

Some of the first studies about the adding of polyolefin fibres to concrete entailed using cylindrical and smooth fibres (63). They concluded that the fibrematrix interface became roughened because of the damage to the fibre surface produced during the mixing process. This roughening formed a mechanical interlock which opposed the extraction of the fibres after crack initiation. Recent published research (64) has found that embossed surfaces provide the highest pull-out resistance followed by flat and crimped fibres. Studies showed that the bond strength of flat 


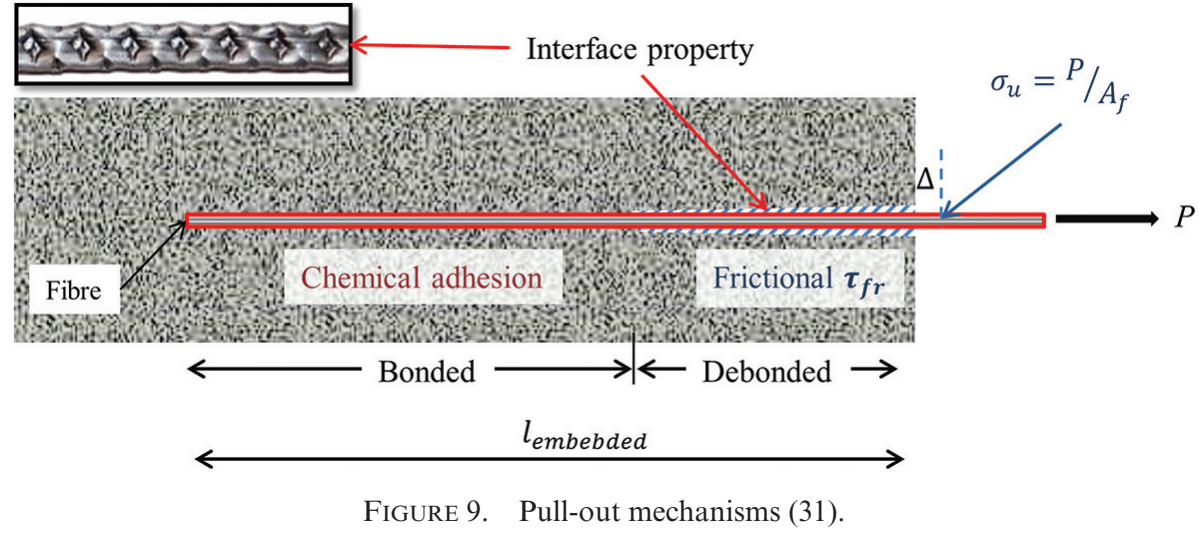

fibres, once mixed with concrete, is enhanced if compared with non-altered fibres and with short embedded lengths. Thus, this advantage is limited for longer embedded lengths and embossed surfaces.

Measurement of pull-out resistance could therefore permit characterisation of the behaviour of a FRC under tensile stress and selection of the most adequate surface for the final purpose. The fibrematrix interactions are logically the main mechanisms of the pull-out processes where the following interactions oppose it (see Figure 9):

- Bond adhesion at the fibre-matrix interface.

- Interfacial shear stress along the fibre-matrix interface.

- Mechanical anchorage in localised transfer points due to geometrical modifications or interface properties.

The energy required to address each of the aforementioned factors differs with the respective variables. The most important ones are the constituent material of the fibre and interaction with the cementitious matrix, the smooth or deformed surface, and the existence of micro-fillers and the geometries of the fibres such as crimped or hooked. It should not be overlooked that the fibres behave in a different way when the embedded length changes. Moreover, the energy absorbed during a pull-out test is also a function of the inclining angle of the fibres which induces a different fracture response depending on the final orientation. An extensive review on straight and hooked steel fibres and pullout response may be found in references $(65,66)$.

In the case of synthetic fibres, it should be noted that the most effective modifications in the shapes in order to enhance the pull-out response have been obtained when roughening the geometry of the fibre surface. The aspect of the pull-out test exhibits the shape shown in Figure 10.

Regarding the modelling of the pull-out behaviour, extensive studies have been carried out with some relating fibre-bridging stress to the crack-opening relation (68). Considering the effects of mechanical

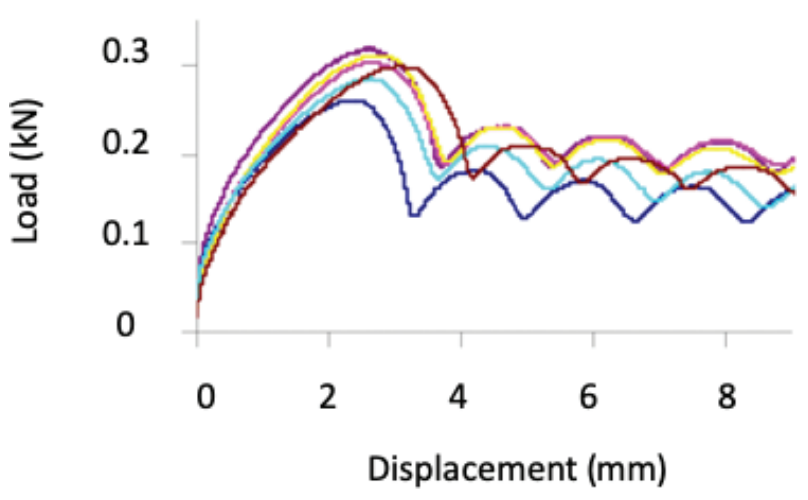

FIGURE 10. Pull-out test of a polyolefin based macro-fibre made by Døssland. Adapted from: (67).

anchorage such as hooked-steel fibres, some semianalytical models have been offered (66). The former reference considered the effect of the hook obtained from experimental results with a straight fibre pullout and the latter used experimental and virtual work principles to describe the load-slip relation.

In general terms, the effects that govern fibre pull-out are the chemical adhesion and interfacial shear stress along the fibre-matrix interface. Some other significant effects are also required in order to assess pull-out behaviour, such as the influence of the inclining angle and the critical embedded length.

Studies of fibre pull-out (69) showed two types of test configuration: the first one was carried out with the aim of achieving the value of the critical length (it also assessed frictional stresses that appear when pulling out the fibre); and the second was performed by means of performing pull-out tests of polyolefin fibres embedded in several lengths and by varying the angle of incidence (70).

In the case of polyolefin fibres, pull-out tests with embedded lengths of five, 10, 15, 20, 25, 30 $\mathrm{mm}$ and several angles $\left(0^{\circ}, 15^{\circ}, 30^{\circ}, 45^{\circ}\right.$ and $\left.60^{\circ}\right)$ have been reported in the literature (69). They were embedded in mortar and SCC. The test setup comprised a metallic frame with two parallel aluminium plates. It was possible to fit the distance between 


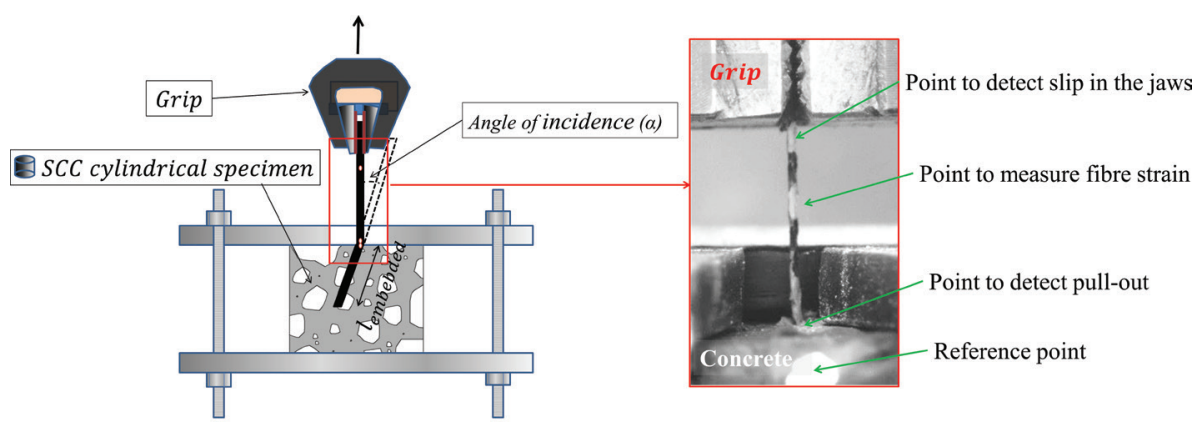

FIGURE 11. Sketch of the test configuration, using concrete specimens and points used to obtain slip, strain or fibre slip inside the jaws. Adapted from: $(31,69)$.

the two plates equal to the height of the cylindrical piece. The schematic description of the test setup is depicted in Figure 11. Video-images recorded during the test helped to detect any non-desired displacement between the elements of the test setup.

The results obtained in (69) are shown in Figure 12. The peak load was maximum for $45^{\circ}$ in the cases of embedded lengths of $10 \mathrm{~mm}$ and 15 $\mathrm{mm}$. In the case of $5 \mathrm{~mm}$ of embedded length the incidence angle in which the test reached the highest peak load was $30^{\circ}$. It should be noted that in the case of fibres embedded $20 \mathrm{~mm}$, it was only possible to pull out the fibre with $0^{\circ}$ of inclining angle.

A microstructural analysis performed in the specimens tested, which may be seen in Figure 13, studied the interface between polyolefin fibre and cement paste where the continuity between the $\mathrm{CSH}$ gel and the polyolefin fibre appeared. Once more, a sound interface between polyolefin fibres and cement paste, without voids or discontinuities, could be perceived. Recent research has also shown that some chemical admixtures may act as a bond improver of the fibres by reducing the width of the interfacial transition zone and the air voids in the interface, leading to enhancements of the residual strengths (44).

\section{FRACTURE RESULTS OF PFRC}

As previously mentioned, the use of structural polyolefin fibres has become an attractive solution in substituting steel-bar reinforcement. In order to do so, fracture tests following the standards EN 14651 (42), RILEM TC- 162 TDF (7) or ASTM 1609 (71) are the reference ones from which the values of residual strengths may be extracted. Figure 14 shows the typical configuration of the fracture tests. Given that the structural requirements depend on these results, the results of the tests have become essential and been performed in several published studies. Reference (21) describes the shape of the fracture behaviour by identifying the turning points of the curves. The first turning point takes place when the loading-process reaches the maximum value and relatively few inelastic processes are evident. This point is known as load at the limit of proportionality $\left(f_{L O P}\right)$ and typically cracks are not perceptible to the naked eye. In the case of the post-cracking load values continuing and increasing after the limit of proportionality, the behaviour of the material would be denoted as hardening. Such behaviour is dissimilar to the softening behaviour that ruled the branch after $f_{L O P}$, as reported in many FRC types and especially for PFRC (21). Despite such softening behaviour, the polyolefin fibres absorb a certain amount of energy released by the concrete in the fracture processes by fibre bridging and change the loading tendency. In such an instant, the curve reaches the minimum post-cracking load $\left(f_{M I N}\right)$, while another up-loading process starts again. The end of the load-increasing-ramp is the third notable point of the curve $\left(f_{R E M}\right)$. The descending slope drawn after $f_{R E M}$ continues until the end of the test. It should be noted that, even at significant deformation states, PFRC does not fail or collapse during the tests. This shows that remarkable improvements in ductility and toughness with respect to plain concrete are conferred by the polyolefin fibres. The values of residual load-bearing capacity or strengths in the curves differ increasingly with fibre dosage, as may be noted in Figure 15, though the main turning point remains at similar deformations. Nevertheless, the amount of fibres has a negligible influence on the peak load recorded in the fracture tests and, therefore, $f_{L O P}$ does not change with fibre dosage being principally determined by the tensile strength of the plain concrete.

One of the major issues that concerns engineers when using PFRC is the reliability of its structural behaviour. In such a sense, significant advances have been made through examination of fibre positioning. Since the number of fibres present in the fracture surface generated during the tests notably influences the values of the residual strengths, predictable tools could significantly enhance material reliability. First advances showed that not all the fibres that appear in the fracture surface influence the residual strengths for the initial crack openings 

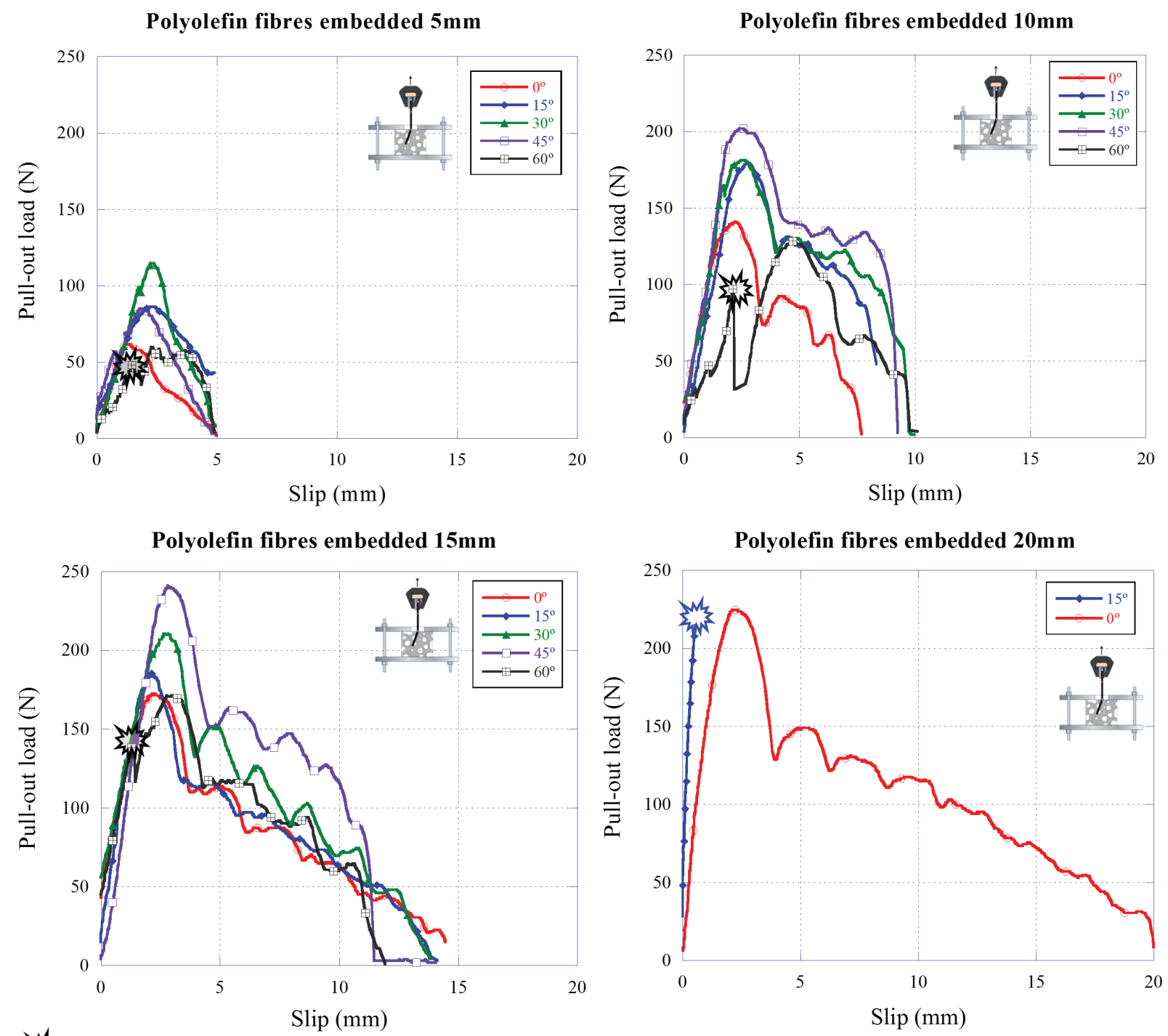

Matrix spalling or fibre rupture

FIGURE 12. Influence of the inclining angle of polyolefin fibres embedded in a SCC (69).Adapted from: $(31,69)$.

commonly used for serviceability limit state (SLS) design. That is to say, a good linear correlation (see Figure 16) may be found when the number of fibres in the lower third of the fracture surface is related to $f_{M I N}$ or $f_{R I}$. Furthermore, when the total number of fibres is correlated with $f_{R E M}$ or $f_{R 3}$ (see section 11), a good linear fit may also be found (as may be noted in Figure 16). These advanced deformations would correspond to ultimate limit state (ULS) design. The cases of SLS and ULS are shown in Figure 17. However, it should be mentioned that due to the experimental scattering the correlations found in Figure 16 do not cross the origin of the plots. If this issue is not considered it might seem that the values of $L_{M I N}$ and $L_{R E M}$ when there are no fibres would not be zero which is not true.
Consequently, the usage of such relations should be limited at dosages of fibres between 3 and 10 $\mathrm{kg} / \mathrm{m}^{3}$.

As already mentioned, given that SCC-flow properties may generate a greater alignment of the fibres (57) an enhancement of the fracture behaviour is detected for the case of steel fibres (55). If the mass of concrete is assumed to flow in layers, the fibres that cross the borderlines would be forced to align with them. Other influences on the final orientation and distribution of the fibres have been assessed by changing the shape and sizes of the formworks (72). This has also been shown in the use of SCC with polyolefin fibres, as described in references $(26-27,29-30)$ and may also be perceived by observing Figure 18. These improvements 
occur mainly owing to changes in fibre positioning that merit thorough study.

Above qualitative considerations, mechanical analysis may be extended by obtaining the orientation factor $\theta$ and its coefficient of variation (CV). When the theoretical number of fibres $(t h)$ crossing the surface is compared with the number of fibres counted in one particular section $(n)$, the denominated coefficient of orientation $(\theta)$ frequently used in previous research (27) could be computed by using expression [1]. Here $V_{f}$ is the fibre volumetric fraction, $A$ is the cross section of the sample and

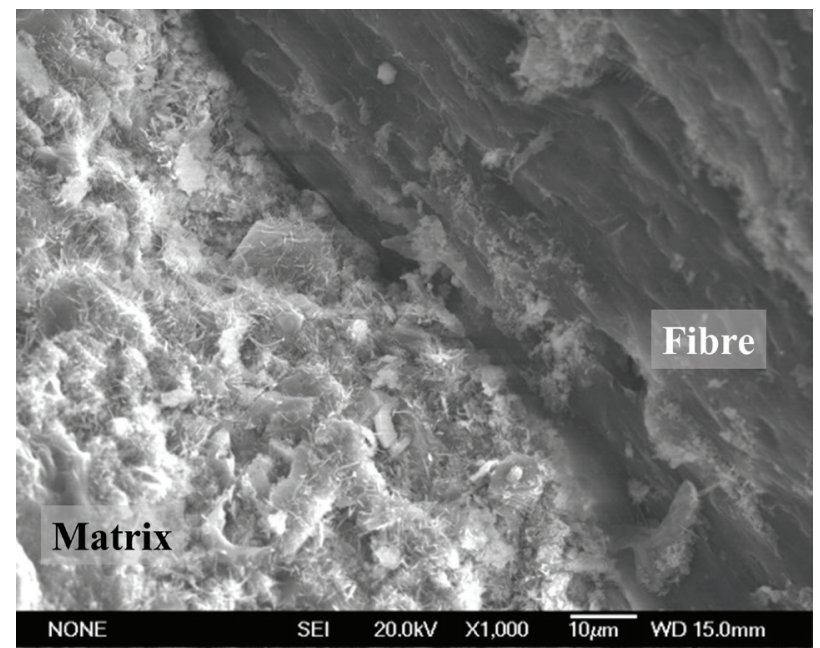

FIGURE 13. Interface between polyolefin fibre and cement paste (69). Adapted from: $(31,69)$.
$A_{f}$ the section of one fibre. This equation was first proposed by Krenchel (73).

$\theta=\frac{n}{t h}=n \frac{A_{f}}{V_{f} A}$

Models used with the aim of predicting the orientation factor have been applied to steel fibres. Dupont and Vandewalle (74) divided the cross-section of a beam into three distinct orientation zones. The bulk zone in the centre of a beam was considered as isotropic. Several authors believed that it was capable of finding numerical values for the orientation factor in the case of a fibre with a straight shape in an infinite environment. These values are summarised in Table 4 . In the proximity of the wall of the mould, the orientation factor increases. The values of the orientation factor at the corners of the rectangular section were also differentiated, given the presence of two walls. If the gravity point of a rigid fibre is placed at a distance lower than half of the length of the fibre, it is geometrically impossible for it to become located perpendicular to the wall. Recent research (75), which also gathered the conclusions of previous models, has shown a model that considered the bendable nature of polyolefin fibres.

The theoretical distribution found in reference (75) may be seen in Figure 19. By summarising the values proposed, the orientation factor that considers the presence of only one wall varies from 0.500 in the bulk to 0.637 in such a wall. In the case of the values of the orientation factor which evaluates the presence of two walls, if the first wall were

Three-point bending tests configuration

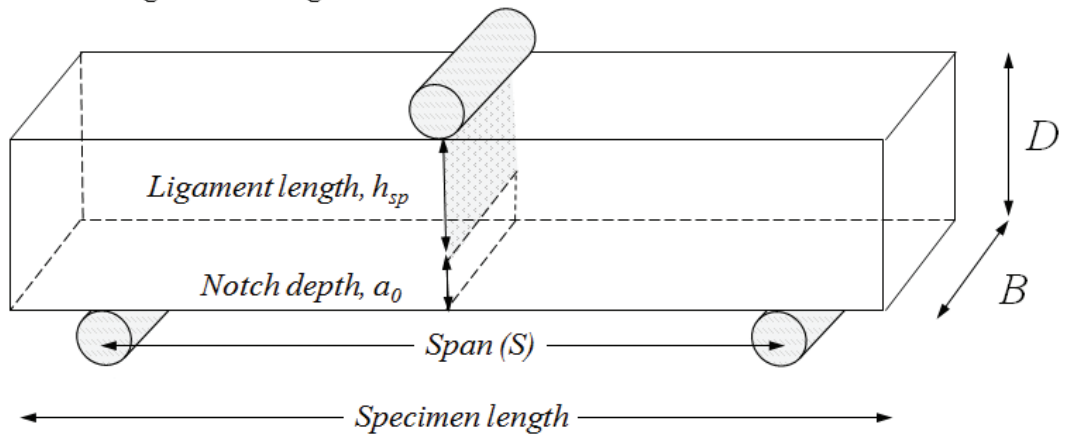

\begin{tabular}{|c|c|c|c|}
\hline Test methodology & Specimen size $(\mathrm{mm})$ & Span of the tes & Ligament size \\
\hline Standards & Length $\mathrm{x}$ height $(D) \mathrm{x}$ depth $(B)$ & $S(\mathrm{~mm})$ & $h_{s p}(\mathrm{~mm})$ \\
\hline EN 14651 & \multirow{2}{*}{$600 \times 150 \times 150$} & \multirow{2}{*}{500} & \multirow{2}{*}{125} \\
\hline RILEM TC162-TDF & & & \\
\hline ASTM C1609/C 1690M-07 & \multirow{2}{*}{$430 \times 100 \times 100$} & \multirow[t]{2}{*}{300} & \multirow{2}{*}{$\frac{2}{3} D \cong 67$} \\
\hline RILEM TC187-SOC & & & \\
\hline
\end{tabular}

FIGURE 14. Configurations of the three-point bending tests. 


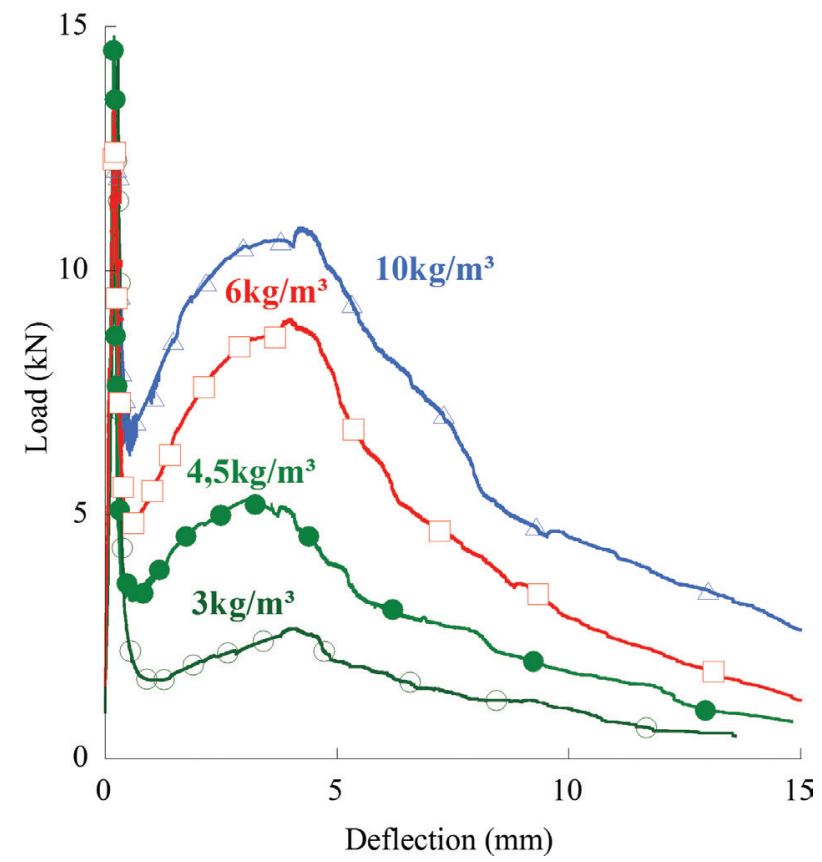

FIGURE 15. Fracture behaviour of PFRC with several contents of fibres. Adapted from: (31).

considered at the edge it would vary from 0.637 to 1.000 in the corner of the two walls. In order to fit a function and develop predictive tools, the variation of the values of the orientation factor was solved (as Figure 20 shows).

In references $(31,75)$ the first analytical model that considered the bendable nature of macro-plastic fibres was prepared. Such a model is related to the projection of the fibres at certain angles. It was stated that the most influencing parameter was the fibre length, since it sets the limit at which the presence of boundaries influence the results. For such a reason, in order to identify assumptions that may consider the effect of bending, a reduction-parameter of fibre length was used. Such a parameter should capture the reduction of the orientation factor observed. In order to do so, the model was built on the base of only affecting the fibre length considered for the calculations. The possible positions of the fibre in the concrete were the same, though a reduction of the projected length was considered due to its own bending. In such a way, the expression required has a geometrical relation with the cord $\left(l_{f i}\right)$ of the circumference drawn by the fibre in each plane, as shown in Figure 21.

The aforementioned model compares predictions with the experimental values obtained in other studies. The model proposed by Alberti et al. had similar values to those obtained experimentally in references (26-27, 29-31, 74). In Figure 22, the theoretical approach and similarity to the experimental values confirmed that the top surface, for synthetic fibres, should not be considered as a boundary.

\section{FLEXURAL RESIDUAL STRENGTHS FEATURED IN THE LITERATURE}

Given that the residual strengths are the values to be considered in the structural design of any concrete element performed with FRC, in this study the foremost results on which analysis has been centred are such strengths. In order to do so, a remarkable number of results of fracture tests have been analysed and compared, with the most representative being placed in Table 5. It should be mentioned that the contribution of fibres to FRC shear behaviour is matter that is discussed in an independent section. In this table strength values extracted from threeand four-bending tests (shown with an asterisk $(*)$ ) can be seen. Regarding the sizes of the specimens, some authors support the idea of comparing rotation angles for each size and configuration (80). However, recent research that uses PFRC has found that the key point is to capture the value of $f_{R I}$ with it being very close to $f_{M I N}$. Consequently, the authors assumed that it was more representative to maintain the results without any further treatment. Those results with smaller beams have been shown in the table with two asterisks $(* *)$. Therefore, Table 5 shows various results from previous references and the data considered most representative, which entailed fibre type, fibre dosage, compressive strength, the reference strength values $\left(f_{L O P}, f_{R I}\right.$ and $f_{R 3}$ and the percentage of $f_{L O P}$ ) and the orientation factor (in some cases it was not reported, though when enough data was available it was computed). Note that the data with three asterisks (***) does not appear as in the original reference as they have been transformed in order to make a meaningful comparison with the rest of data of the table.

The volume fraction and residual strengths acquired from the results were considered as the most reliable parameters in order to allow comparison of the values obtained. Figure 23 shows the relation $f_{L O P} / V_{f}, f_{R I} / V_{f}$ and $f_{R 3} / V_{f}$ of the values shown in Table 5. As may be perceived, the degree of scattering around $f_{L O P}$ is higher given that these values are strongly dependent on the characteristics of the concrete matrix. Regarding the values of $f_{R I}$ and $f_{R 3}$, it may be seen that they are closer to each other with the average values being 250 for $f_{R 1}$ and 300 for $f_{R 3}$.

\section{POLYOLEFIN FIBRES COMBINED STEEL FIBRES}

Steel and synthetic fibres are the most used in FRC and their mechanical contribution have gathered significant importance in many applications. In such applications, the alternative of using (at the same time) several concrete modern technologies is also assumed, with one option being a combination of various types of fibres. The field opens new study possibilities. However, the present state of the art 

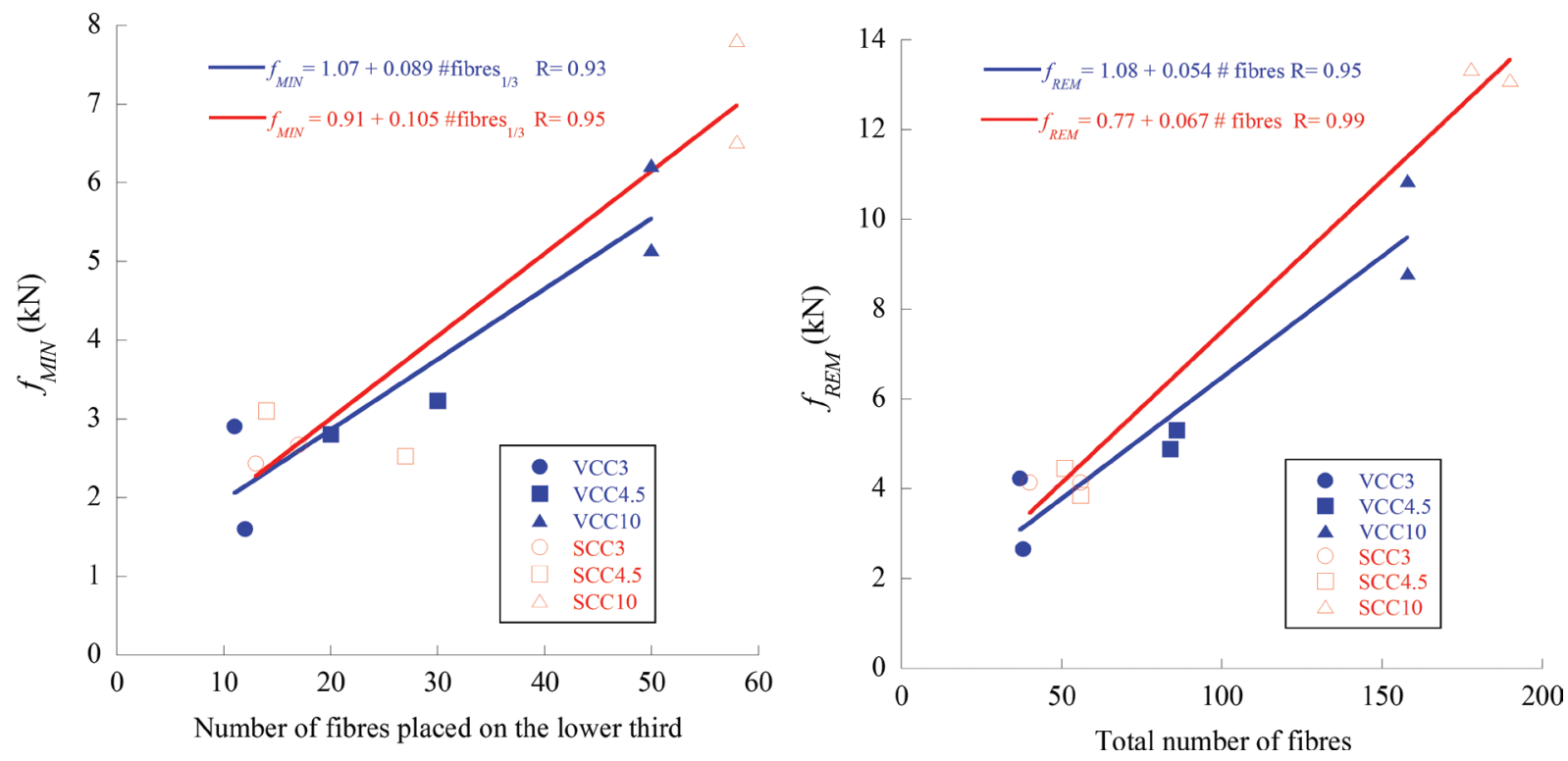

FIGURE 16. Relation between the number of fibres present in the fracture surfaces and the residual loads $L_{M I N}$ and $L_{R E M}$ for vibrated conventional PFRC (VCC) and self-compacting PFRC (SCC). Tests performed following EN-14651 in reference (27).
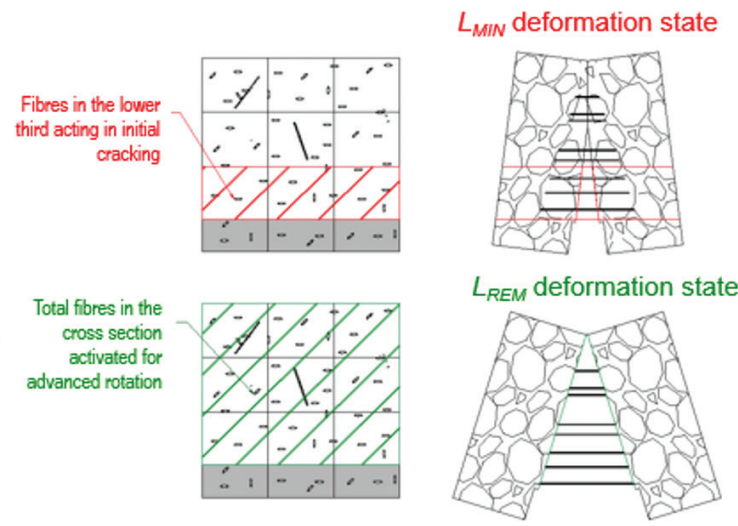

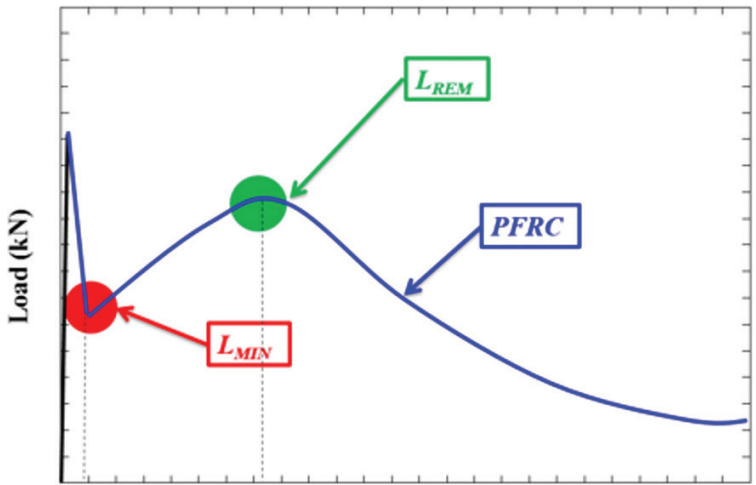

Deflection (mm) | Crak opening (mm)

FIGURE 17. Deformation states of SLS or ULS. Adapted from: $(31,41)$.

has a limited background regarding the combination of steel fibres and micro-polymer fibres. Given that most of the research has compared structural polyolefin fibres with steel-hooked fibres in several types of concrete or mechanical tests in reference (81), a decision was made to evaluate the combination of these two fibres. The design considerations were based on the best performance of each fibre type: initial crack openings for short steel-hooked fibres and polyolefin fibres for larger deformations (depicted in Figure 24). The results of the study concluded that synergies in the combined-use of the two fibre types permitted orientation factors to be obtained. The increment of energy consumption that might be considered attributable to such synergies is highlighted in green in Figure 25. This shows one of the future lines to improve the use of fibres in the construction field: the search for the appropriate fibre cocktail for each application. These combinations have been used to reduce the amount of steel (and seeking a more sustainable concrete design) (91) and obtain improved FRC mechanical properties in certain applications (40).

\section{FRC CHARACTERISATION AS A STRUCTURAL MATERIAL}

The first efforts to include FRC in the structural codes date back to the mid-twentieth century when the American Concrete Institute (ACI) Committee 544 produced design considerations regarding the reinforcement of concrete by adding steel fibres to the mix. In 1992, the German Code (92) proposed a $\sigma-\varepsilon$ relationship for the structural design of tunnel linings, using steel fibres in concrete. In the last 15 years codes and guidelines have been published 


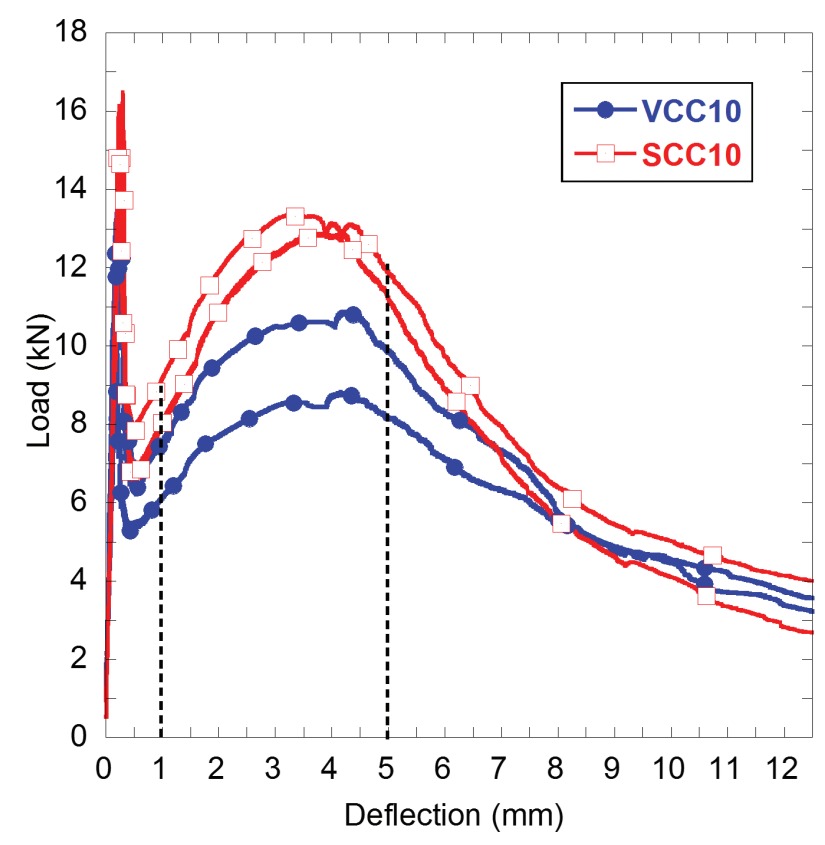

FIGURE 18. Load-deflection curves obtained in fracture tests of VCC and SCC with $10 \mathrm{~kg} / \mathrm{m}^{3}$ of polyolefin fibres (27).

TABLE 4. Values provided by the models and the main references (52).

\begin{tabular}{lcc}
\hline Probabilistic boundaries & 2-D & 3-D \\
\hline Buffon's needle problem & $2 / \pi=0.637$ & - \\
Soroushian and Lee $(3 ; 76 ; 77)$ & 0.637 & 0.405 \\
Dupont \& Vandewalle $(74 ; 78 ; 79)$ & 0.600 & 0.500 \\
Alberti, Enfedaque \& Gálvez (75) & 0.637 & 0.500 \\
Simplified $\theta(31)$ & 0.667 & 0.444 \\
\hline
\end{tabular}

in the United States, Japan and many European countries that enable the practical design of structures which consider fracture mechanics concepts that consider the post-cracking residual strength of FRC under tensile stresses. In response to their own internal demand, in European countries such as Germany (93) and Spain (9) codes and design guidelines have been produced and even revised. A review of the European codes is provided in (85). In order to relate the structural requirements and fracture behaviour of FRC, Figure 26 has been plotted based on fib Model Code (5) and EN-14889 (13, 14).

At present, FRC appears in the new CEB-FIB Model Code 2010, MC2010 (5) and is considered a reference for newer revisions of Eurocode 2 (94) and European guidelines. Some of the main features of Model Code 2010 are listed below.

It establishes a material classification based on two post-cracking residual strengths at certain CMOD values which define SLS, $(\mathrm{CMOD}=0.5$ $\mathrm{mm})$ and ULS, $(\mathrm{CMOD}=2.5 \mathrm{~mm})$. The CMOD curves are to be assessed by three-point bending tests as per UNE-EN 14651 (42).

It defines two simplified $\sigma-w$ constitutive diagrams in bending test results. A rigid plastic model and a linear post-cracking model, with each included for hardening and softening materials (as shown in Figure 27).

The Model Code, considering that continuum mechanics is governed by stress-strain $(\sigma-\varepsilon)$ constitutive relationships while fracture mechanics is governed by a stress-crack opening $(\sigma-w)$ law, introduces the concept of the structural characteristic length, $l_{c s}$, for the structural element. This concept, initially proposed by Hillerborg (95),
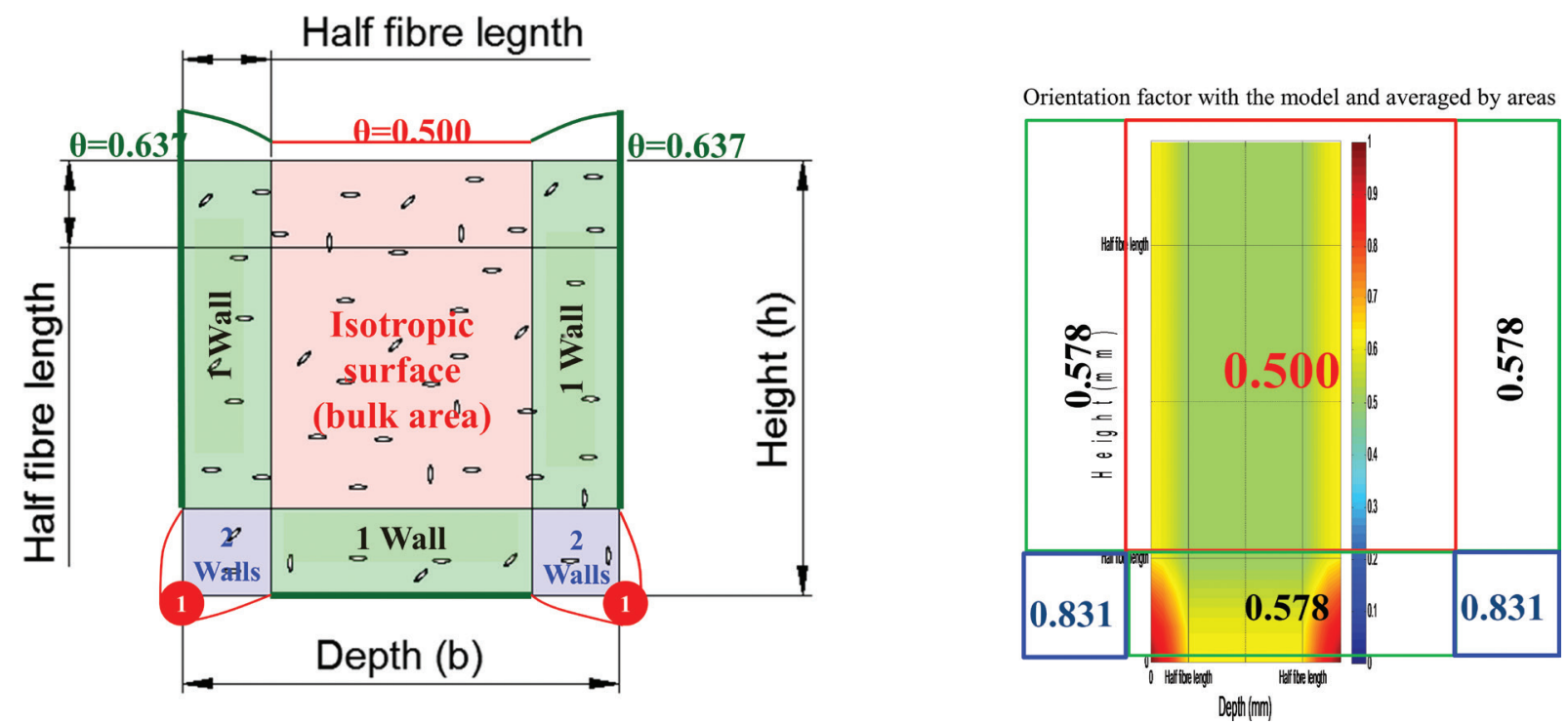

FIGURE 19. Probability distributions in a rectangular section (31). 


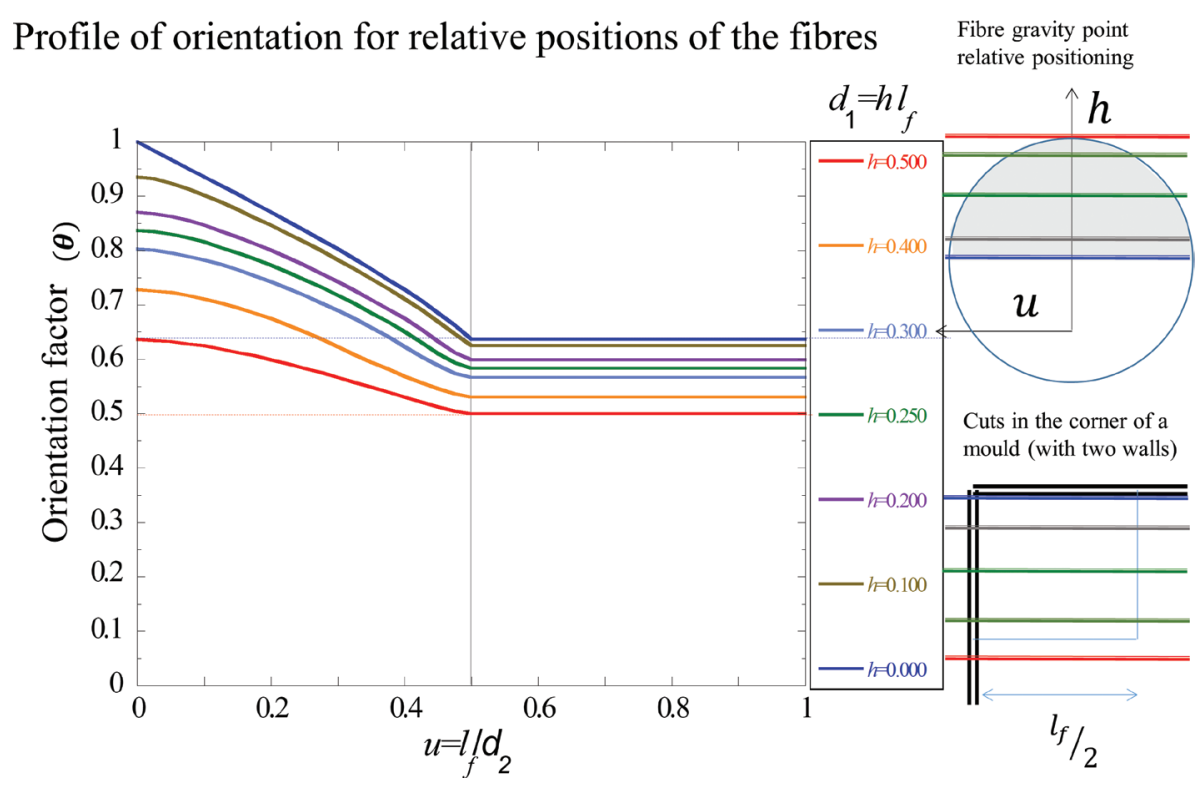

FIGURE 20. Profile of the value of the orientation factor as a function of the distance between fibre gravity point and the each of the two walls (31).

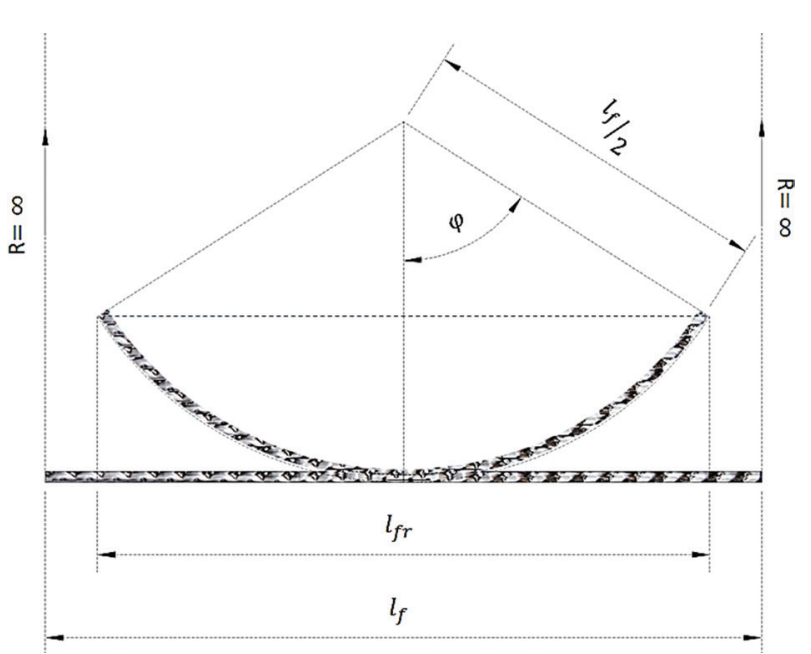

FIGURE 21. Fibre bending and reduction of its mean projection (31).

represents a "bridge" that connects continuous and fracture behaviours by defining the strain as $W / l_{c s}$. The values of $l_{c s}$ have been proposed by various authors, as may be perceived in Table 6, with $h$ being the height of the concrete element. The proposed general formulation to obtain this parameter may be seen in expression [2].

$\varepsilon(y)=\varepsilon_{u}+\varepsilon_{w}=\frac{\sigma_{u}}{E_{c}}+\frac{w}{l_{c s}}$

It defines a simplified model to compute the ultimate residual tensile strength under uni-axial stress through the residual nominal bending strength as shown in Figure 28.

It distinguishes between structural and nonstructural types of fibres, similar to the Spanish Structural Concrete Code (9). Fibres may be considered as structural if they have a high modulus of elasticity and, if used in certain dosages, they provide the FRC with a minimum performance in terms of toughness. This distinction implies a significant change in FRC design, given that it extends the range of fibres that may be used for structural purposes and allows partial or even total substitution of standard reinforcing bars by structural fibres.

Apart from the approach taken by the cited standards, the constitutive relation of PFRC has recently been obtained by means of inverse analysis. The experimental results were thoroughly reproduced with the use of cohesive models where tri-linear softening functions were implemented. By varying the three points that define the tri-linear softening functions, it was possible to predict the behaviour of PFRC for low-, medium- and high-fibre dosages. Figure 29 (100) shows the softening functions and the results of the numerical simulations.

The shape of the softening functions and denomination of the turning points can be seen in Figure 30. Based on the experimental data available in previous studies $(21,30)$, a relation between the volume fraction of fibres and the minimum strength of PFRC has been found. Through using such a relation and the values obtained of $C_{M I N}$, it was possible to fit the evolution of the angle $(\phi)$ with fibre dosage $\left(V_{f}\right)$ according to equation [3]. Regarding the maximum post-peak stress, it would be necessary to define parameter $\lambda$ which appears in 
PFRC with $6 \mathrm{~kg} / \mathrm{m}^{3}$ of $60 \mathrm{~mm}$ long polyolefin fibres

\begin{tabular}{|c|c|c|}
\hline $\begin{array}{l}\text { Mean distribution of } \\
\text { fibres in VCC }\end{array}$ & $\begin{array}{l}\text { Mean distribution of } \\
\text { fibres in SCC }\end{array}$ & $\begin{array}{c}\text { Theoretical distribution } \\
\text { of fibres }\end{array}$ \\
\hline
\end{tabular}

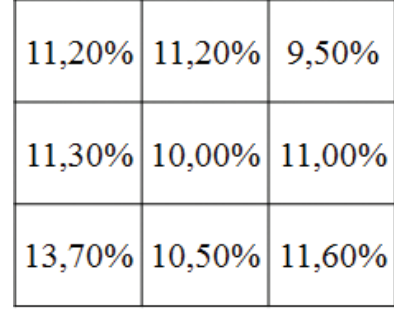

(a)

\begin{tabular}{|l|l|l|}
\hline $10,70 \%$ & $10,20 \%$ & $12,70 \%$ \\
\hline $10,20 \%$ & $9,90 \%$ & $10,20 \%$ \\
\hline $12,30 \%$ & $11,10 \%$ & $12,70 \%$ \\
\hline
\end{tabular}

(b)

\begin{tabular}{|l|l|l|}
\hline $10,80 \%$ & $9,90 \%$ & $10,80 \%$ \\
\hline $10,80 \%$ & $9,90 \%$ & $10,80 \%$ \\
\hline $13,00 \%$ & $10,80 \%$ & $13,00 \%$ \\
\hline
\end{tabular}

(c)

FIGURE 22. Mean experimental distributions of fibres in 20 surfaces with 150x150 $\mathrm{mm}^{2}$ square cross-section produced with of PFRC with $6 \mathrm{~kg} / \mathrm{m}^{3}$ polyolefin fibres $60 \mathrm{~mm}(31)$.

expression [4] as the product of the orientation factor $(\theta)$, the volumetric fraction $\left(V_{f}\right)$ and the percentage of fibres pulled out. The corresponding stress value of $C_{R E M}$ can be computed with expression [5], by multiplying $\lambda$ by the ultimate tensile strength of the fibres $\left(\sigma_{u}\right)$. In this case, in order to find $C_{R E M}$, a linear fitting was found that could be computed by following equation [6]. Regarding the assessment of $C_{R E M}$ coordinates, the values of crack opening were equal to 2.25 for all the concrete formulations mentioned above. Although the fibre dosage affected the stress values, the deformation state at which the fibre failure took place was constant. This was in accordance with the experimental results shown in $(21,27)$. Furthermore, it also agreed with the assumption of fibres collapsing for certain equal deformations for a fixed fibre length. These two relations enable the softening function for any type of PFRC to be obtained if the dosage and the fibres characteristics were known. By including such a softening function in the implemented numerical model, the fracture behaviour of any PFRC can be obtained with a reasonable degree of accuracy. Consequently, having defined the tensile post-peak behaviour with the softening function and with the compressive behaviour being analogous to a conventional concrete, the constitutive relation of the material could be defined.

Moreover, with these values it is possible to compute the reference length $\left(l_{\text {ref }}\right)$ that relates the crack opening with the strains of the elastic branch by expression [7]. In expression [7], $\varepsilon_{u}$ is the ultimate elastic deformation considered as 0.012 and $\varepsilon_{u f}$ is the ultimate elongation of the fibre set to $0.10(10 \%)$. This is based on the properties stated by the manufacturer. With such values and $2.25 \mathrm{~mm}$ of crack width $(w)$, the reference length, $l_{\text {ref }}$ becomes $25.6 \mathrm{~mm}$. This was in accordance with most of that reported in the literature: approximately half fibre length (or the height of the ligament) (98) or close to one third of the depth of the specimen. The final coordinates for four fibre dosages of the main turning points found in the study can be seen in Table 7 .

$$
\begin{aligned}
& \phi=-3.6046+5.0625 \cdot\left(1-e^{-6.55 \cdot V f}\right) \Rightarrow R^{2}=0.99996 \\
& \lambda=(1-\% \text { Pulled }- \text { out }) \cdot V_{f} \cdot \theta \\
& \sigma_{\text {CREM }}=\lambda \cdot \sigma_{u} \\
& \sigma_{C R E M(\text { linear })}=391.6 \cdot \theta \cdot V_{f} \cdot \sigma_{u} \\
& \varepsilon_{u f}=\varepsilon_{u}+\frac{w}{l_{\text {ref }}}
\end{aligned}
$$

The proposed constitutive model provides a significant tool for structural designers in order to consider the mechanical contributions of the fibres in the post-cracking stages. The accurate reproduction of the experimental results permits a confident use of the model proposed. Therefore, designers might take full advantage of the presence of the polyolefin fibres, widening the everyday application of PFRC in the building industry. Additionally, this might also be considered as a remarkable advance for optimising the amount of steel bar reinforcement used in civil engineering applications which might contribute to a more sustainable development (100).

\section{SHEAR BEHAVIOUR OF PFRC}

Various studies that examine the shear behaviour of SFRC have shown that remarkable improvements, and considerable reduction or even total substitution of steel stirrups, may be obtained 


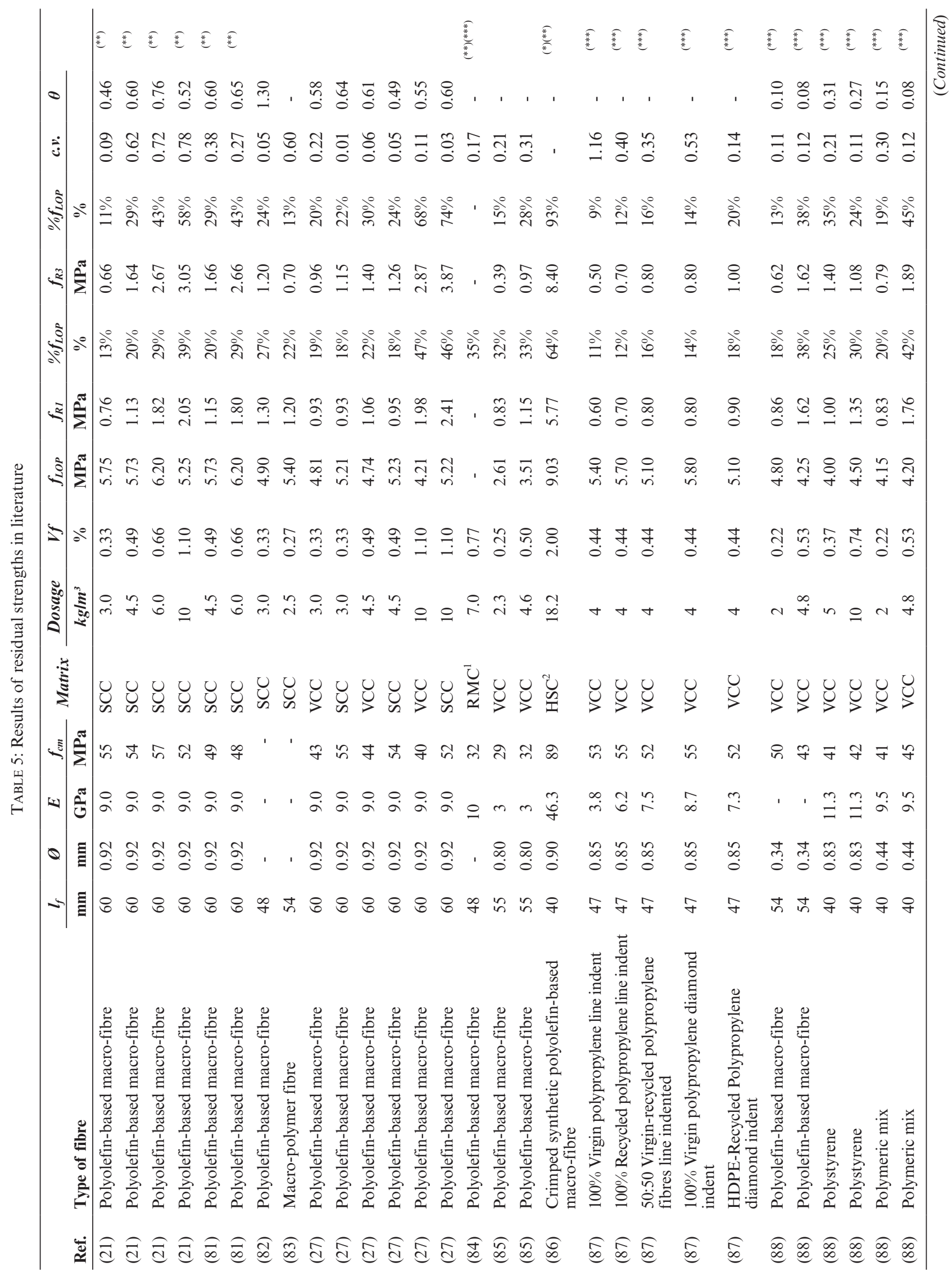


20 M.G. Alberti et al.

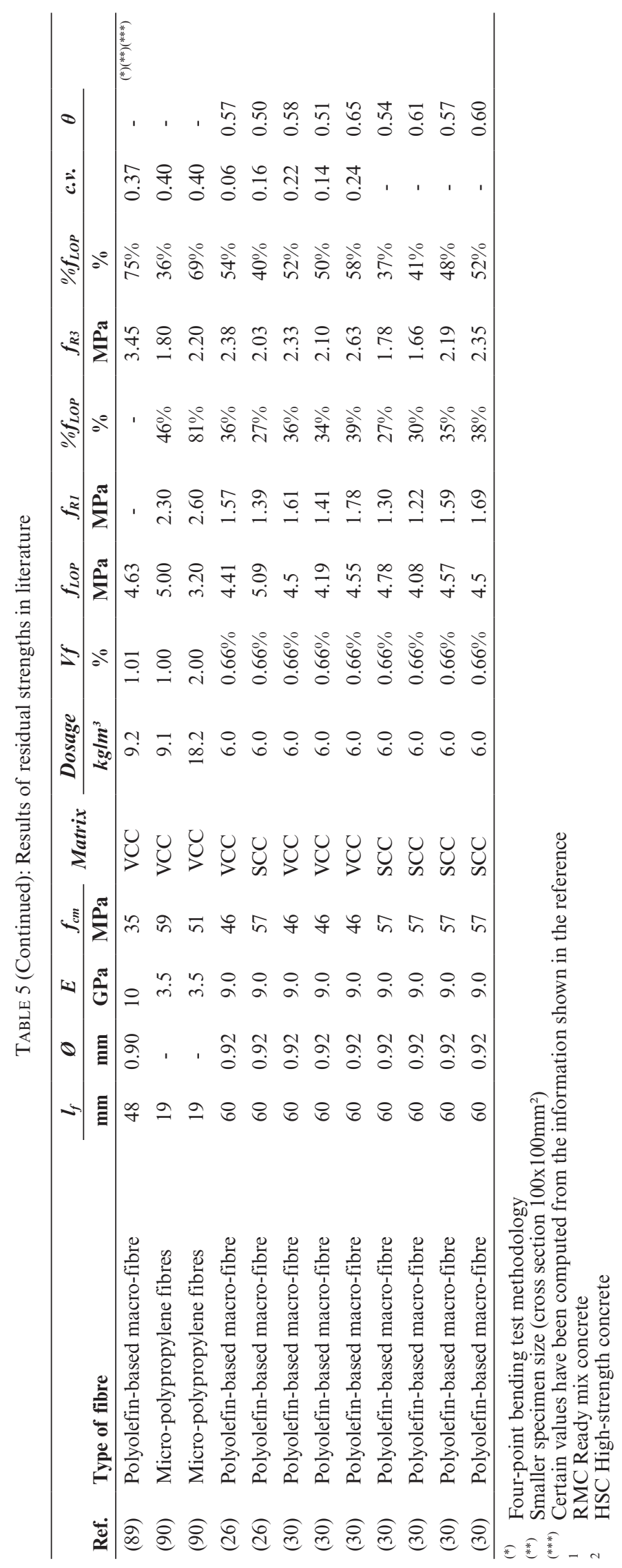


by considering the contribution of steel fibres as shear reinforcement. Nonetheless, there remains a degree of uncertainty in determining and quantifying with accuracy the resistant mechanisms of FRC under shear stress when optimising the reinforcements in each structural problem $(101,102)$. In order to address this, the mechanisms mobilised in a cracked element may be identified as follows:

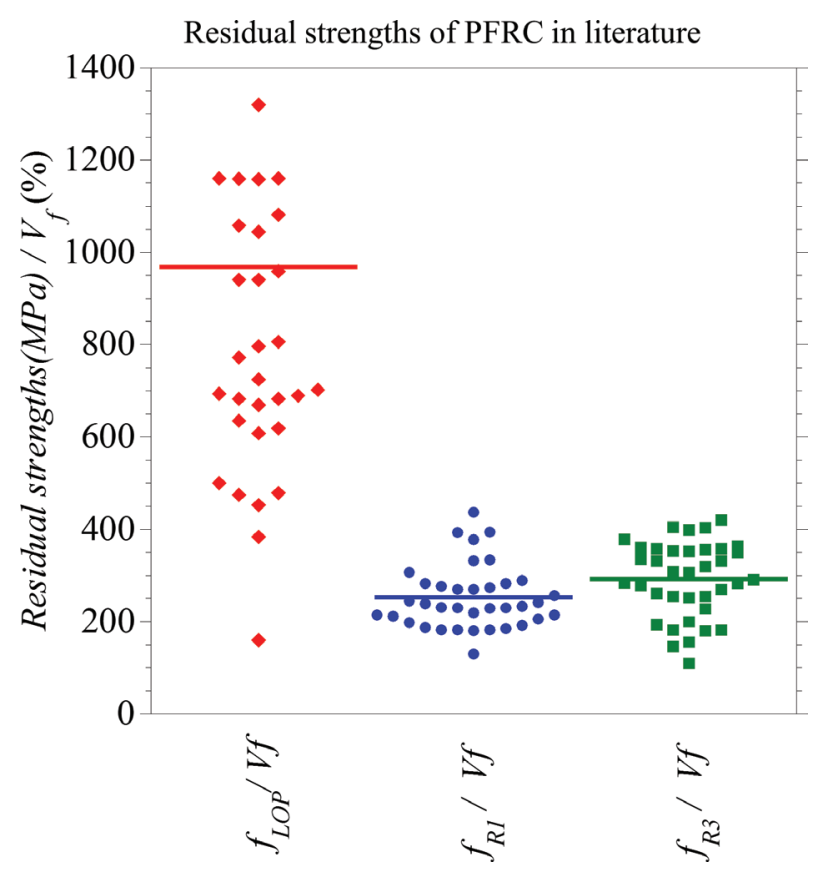

FIGURE 23. Representative values of the relation of strengths and volume fraction $\left(f_{L O P} / V_{f}, f_{R I} / V_{f}\right.$ and $\left.f_{R 3} / V_{f}\right)$ of macrosynthetic fibres found in the literature.

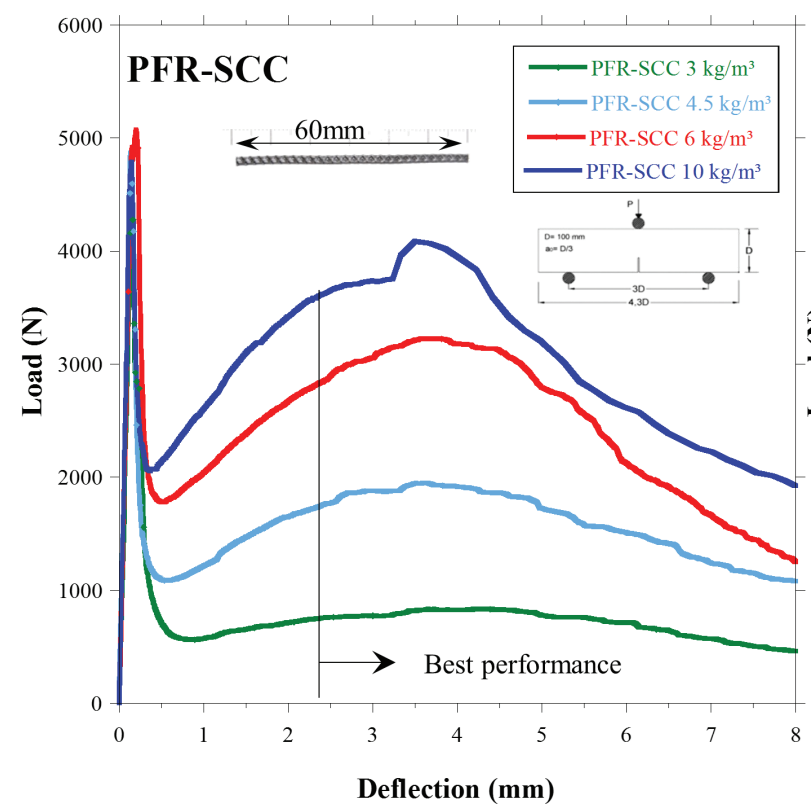

tangential stresses in the area of uncracked concrete (the area under compression in the cross-section of the beam), engagement of the aggregates (aggregate interlock or shear friction at the crack), a pin effect of the longitudinal reinforcement (dowel action), an arch effect and residual tensile stress across cracks (103).

In addition, and in the case of PFRC, research has been focused on assessing the residual tensile strength by standard tests when the material is subjected to fracture in mode I. Once the postcracking residual strengths are obtained in such tests, constitutive relations may be deduced by following certain standards (32) or obtained by cohesive models through direct $(7,71)$ or inverse analyses (42). However, there is a lack of research that deals with the behaviour of PFRC under shear stresses.

The absence of a standard test regarding pure shear and PFRC has possibly impeded research in the mechanical behaviour of the material under fracture in mode II. Among the proposed methods, the push-off test has been shown to supply reliable information (104-106). The configuration of this type of test may be seen in Figure 31. Recent research has assessed the shear behaviour in the case of PFRC, (107) showing that it is possible to achieve significant improvements as in the case of SFRC. The curves provided in Figure 32 show that the push-off tests for PFRC reach shear strength values that may be applied in structural design, reducing the amount of shear reinforcement by the presence of fibres. As in the case of bending stresses, the values of the maximum shear strength were linked to the properties of the concrete

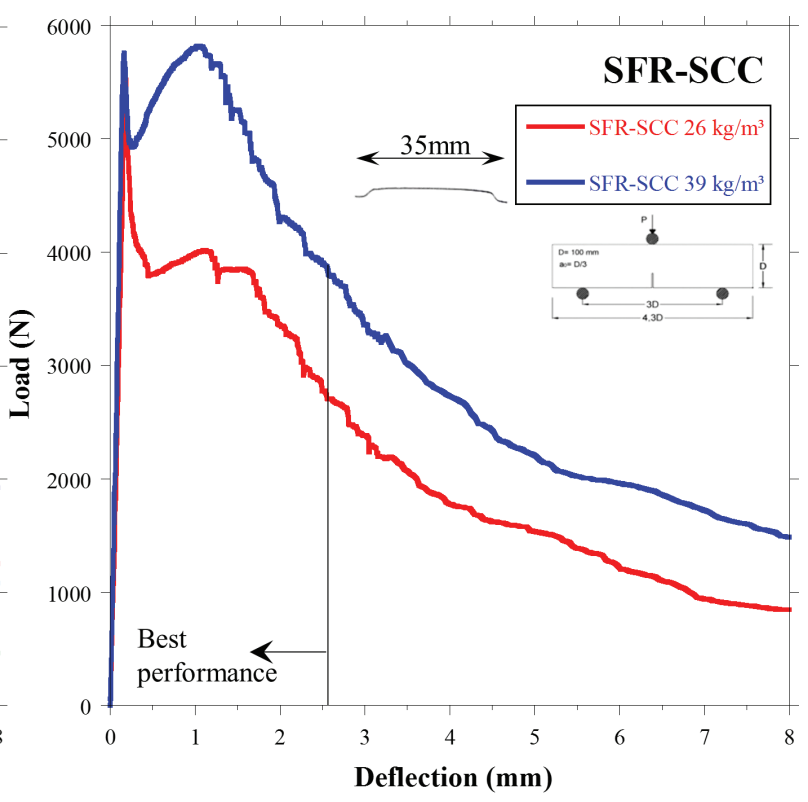

FIGURE 24. Sketch of the best performance of each fibre type. Adapted from: (81). 


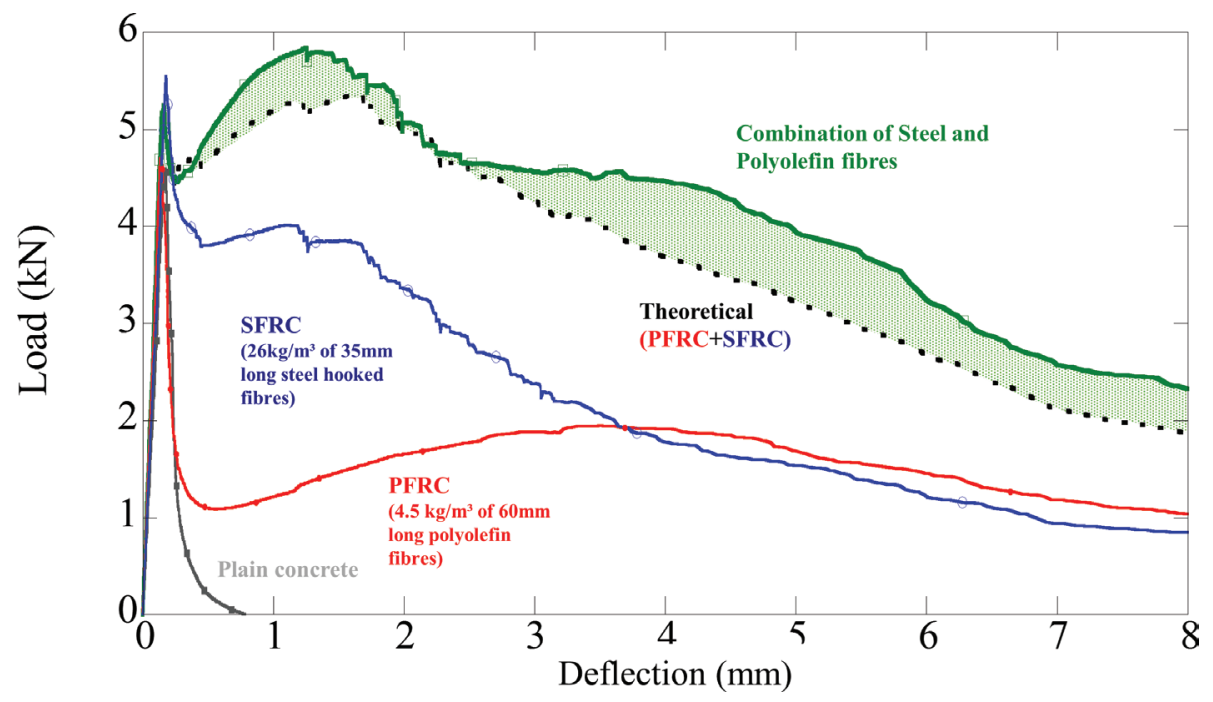

FIGURE 25. Fracture results of the combination of steel hooked fibres and polyolefin fibre and the sum of the residual contributions of mono-fibre-reinforced mixtures. Adapted from: (40).

\section{Requirements for structural fibres in MC2010 and EHE-08}

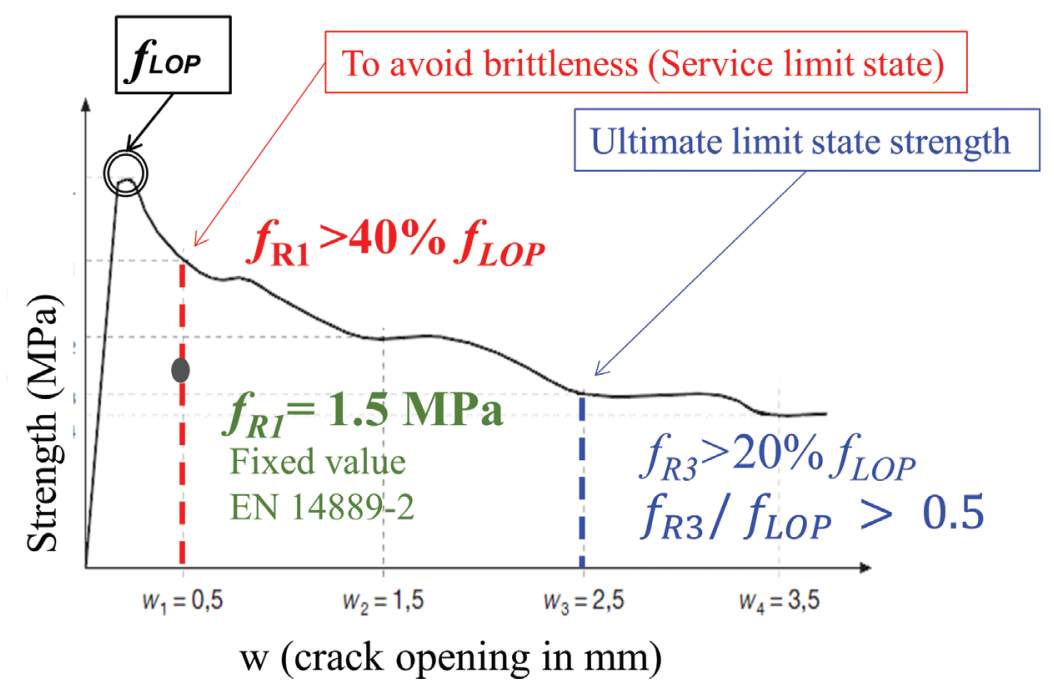

FIGURE 26. Requirements of the standards for structural fibres.

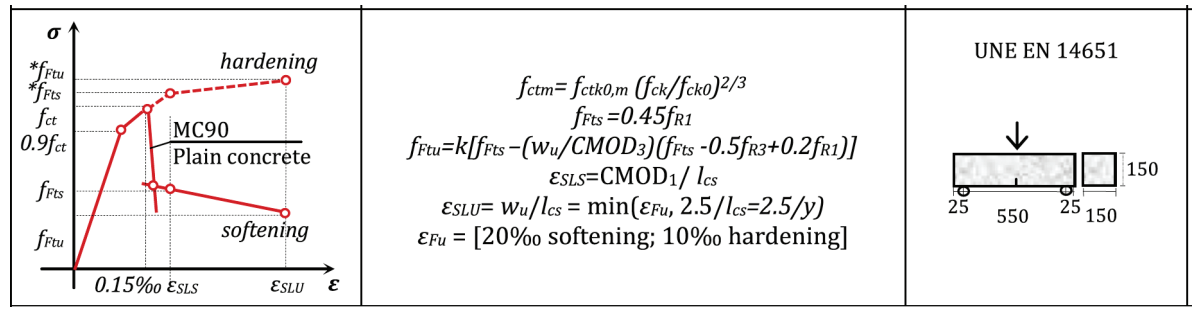

FIGURE 27. Constitutive models and tests of MC2010. Adapted from: (85). 
TABLE 6. Proposed values for the reference length (96)

\begin{tabular}{llc}
\hline Reinforcement type & $\boldsymbol{l}_{c s}$ & Reference \\
\hline SFRC & $h / 2$ & $(7 ; 97 ; 98)$ \\
& $2 h / 3$ & $(99)$ \\
& $H$ & $(8 ; 5)$ \\
& $2 h$ & $(96)$ \\
SFRC and & $\operatorname{Min}\left[s_{m} ; h / 2\right]^{*}$ & $(98)$ \\
reinforcing bars & $\operatorname{Min}\left[s_{m} ; y\right]^{*}$ & $(8 ; 5)$ \\
& $\operatorname{Min}\left[s_{m} ; h\right]^{*}$ & $(96)$ \\
\hline
\end{tabular}

${ }^{*} s_{m}$ was estimated with the Eurocode -2 (94)
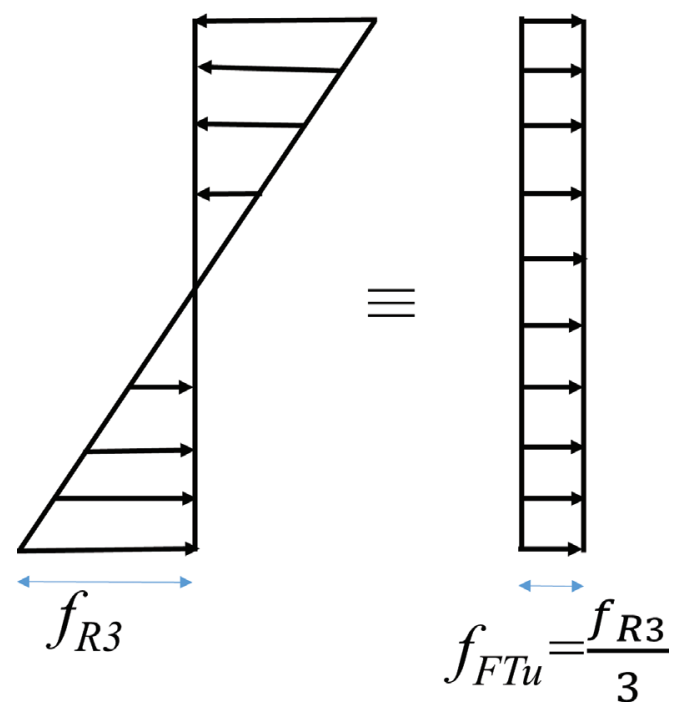

FiguRE 28. Simplified model adopted to compute the ultimate residual tensile. Adapted from: (16).

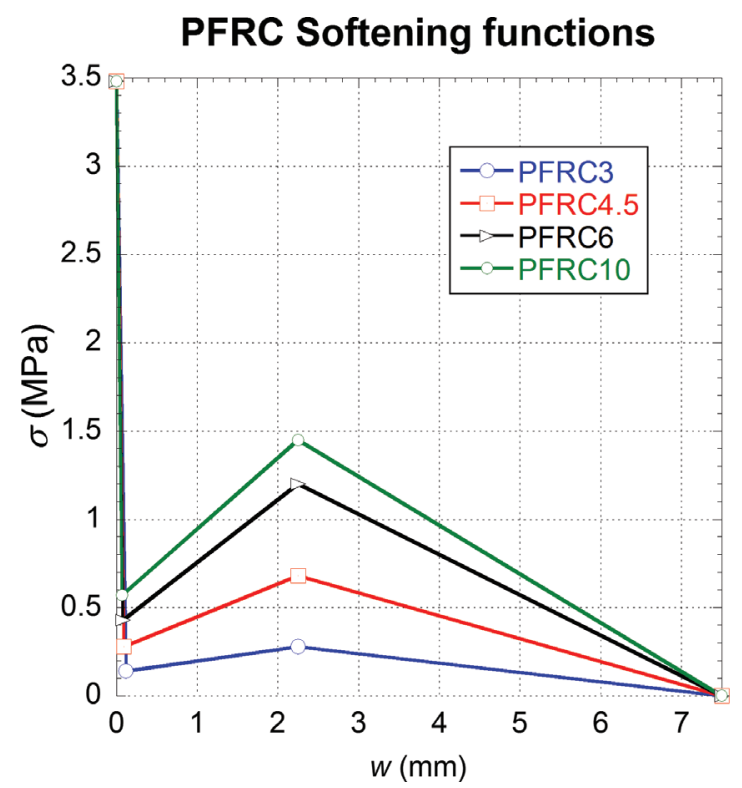

matrix. Furthermore, the values of the residual shear strengths were associated with fibre dosage and positioning. Therefore, it was concluded that the residual shear strength is governed by the presence of fibres. The behaviour of PFRC under shear stresses showed that fracture processes increased ductility of the concrete and the specimens had substantial shear-bearing capacities up to crack shear displacement (CSD) of $6 \mathrm{~mm}$.

\section{CONCLUDING NOTES}

This contribution has examined the knowledge acquired about PFRC to enhance its application and use in the building and construction industries. The development of macro-polyolefin fibres with

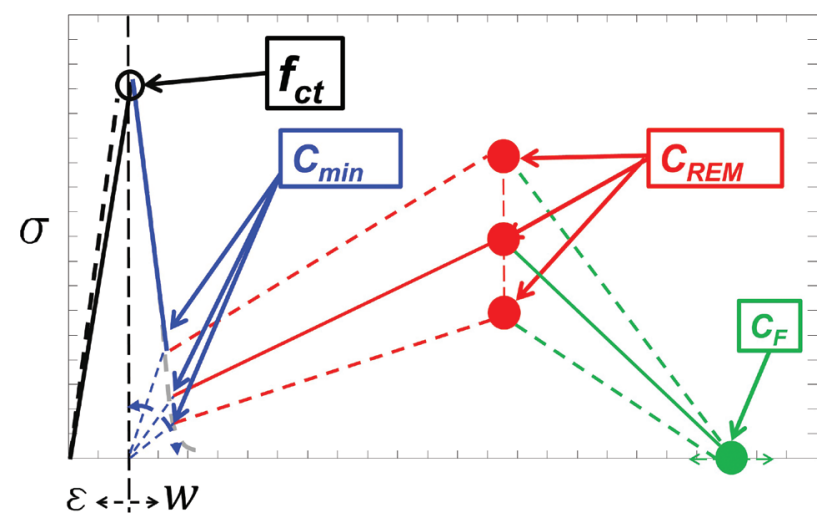

FIGURE 30. Scheme of the constitutive relations for PFRC (31).

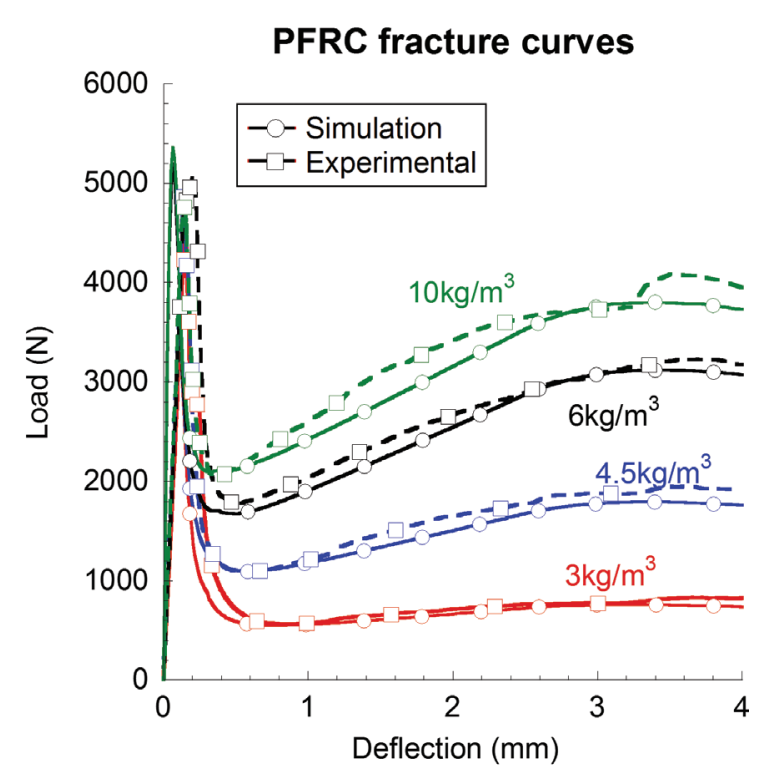

FIGURE 29. Softening functions (left) and comparison among simulated and experimental results (right). Adapted from: (100). 
TABLE 7. Turning points of the constitutive relations in reference (100).

\begin{tabular}{|c|c|c|c|c|c|c|c|}
\hline & \multicolumn{3}{|c|}{$C_{\min }$} & \multicolumn{2}{|c|}{$C_{R E M}$} & \multicolumn{2}{|c|}{$C_{F}$} \\
\hline & $\mathbf{w}(\mathbf{m m})$ & $\sigma(M P \alpha)$ & $\phi(\mathrm{rad})$ & $\mathbf{w}(\mathbf{m m})$ & $\sigma(M P \alpha)$ & $\mathrm{w}(\mathbf{m m})$ & $\sigma(M P \alpha)$ \\
\hline PFRC-3 & 0.12 & 0.14 & 0.88 & 2.25 & 0.28 & 7.5 & 0 \\
\hline PFRC-4.5 & 0.09 & 0.28 & 1.25 & 2.25 & 0.68 & 7.5 & 0 \\
\hline PFRC-6 & 0.08 & 0.43 & 1.39 & 2.25 & 1.20 & 7.5 & 0 \\
\hline PFRC-10 & 0.07 & 0.57 & 1.45 & 2.25 & 1.45 & 7.5 & 0 \\
\hline
\end{tabular}
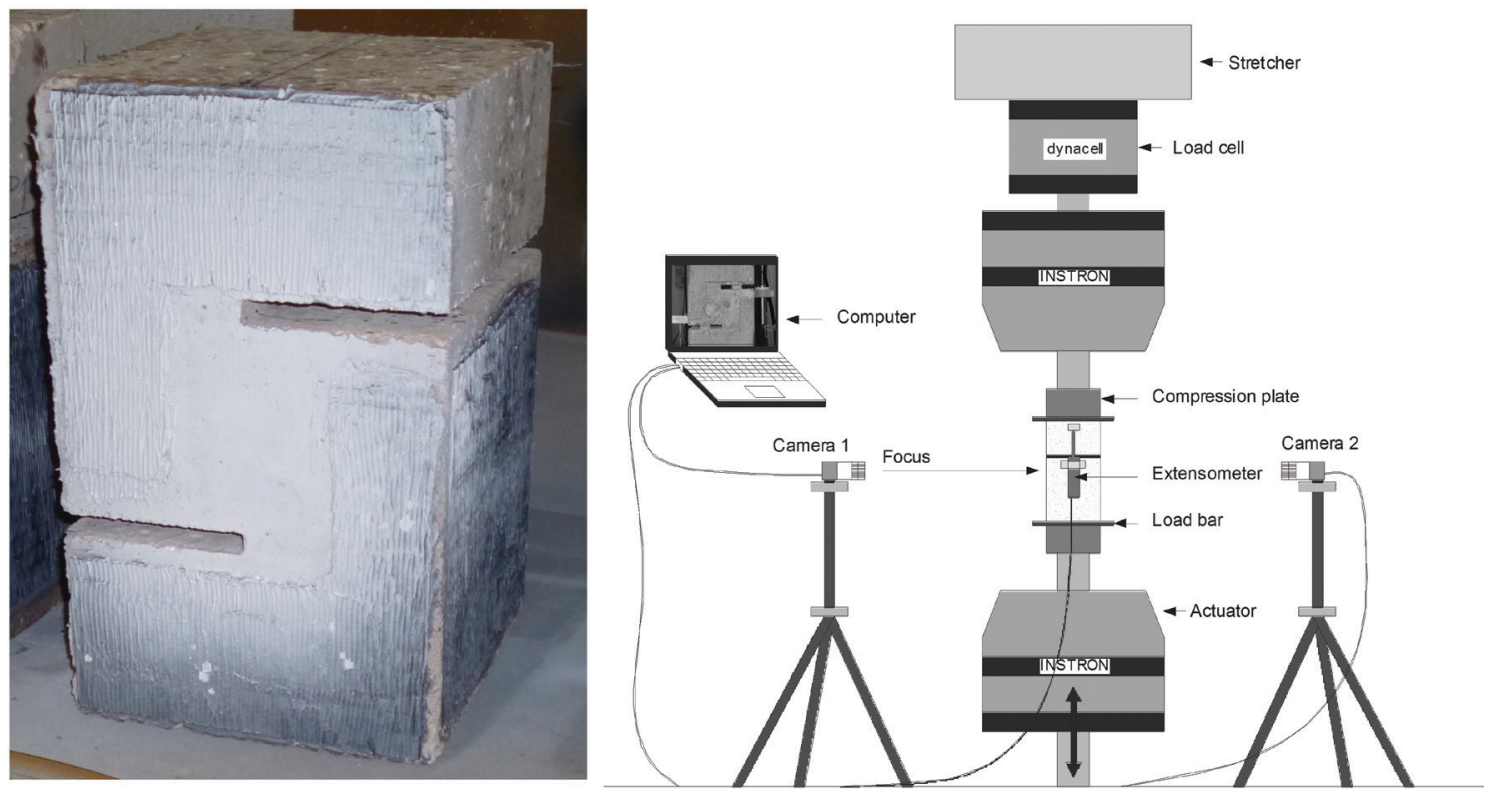

Figure 31. (a) Push-off test setup; (b) Specimen push-off tested. Adapted from: (107).

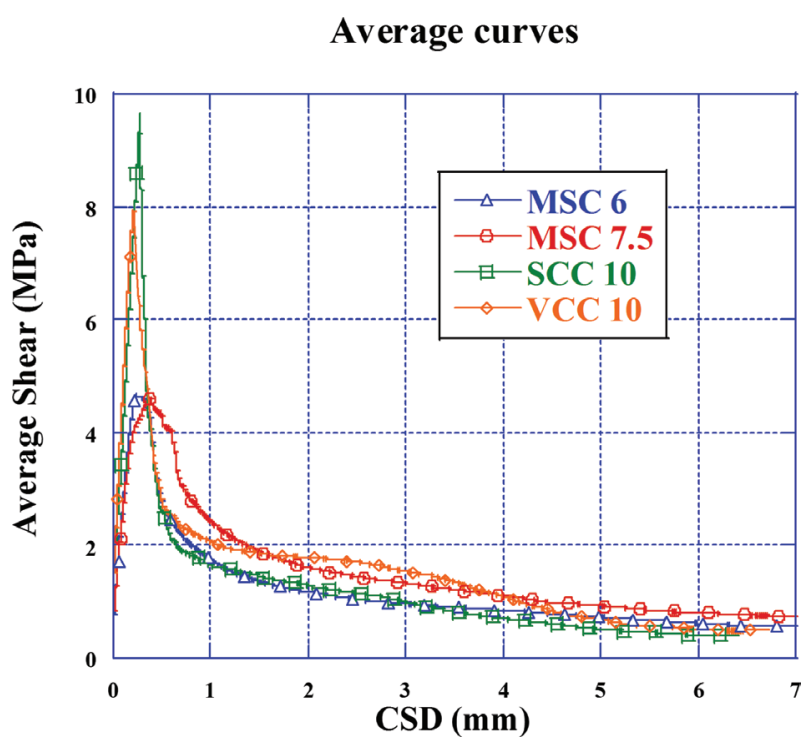

FIGURE 32. Average curves CSD vs. average shear $\left(\tau_{\text {aver }}\right)$ of the four types of concrete (107). The figure shows the results obtained with a medium-strength concrete with 6 and $7.5 \mathrm{~kg} /$ $\mathrm{m}^{3}$ of polyolefin fibres (MSC6 and MSC7.5), a conventional vibrated concrete with $10 \mathrm{~kg} / \mathrm{m}^{3}$ (VCC10) of polyolefin fibres and a self-compacting concrete with $10 \mathrm{~kg} / \mathrm{m}^{3}$ of polyolefin fibres. improved mechanical properties and embossed surfaces has given place to increased use in structural concrete based on studies that have shown a remarkable performance in both fresh state and hardened state. It should be noted that the post-peak behaviour that polyolefin fibres confer to concrete has enabled the use of PFRC in many architectural and infrastructure applications. In addition, the chemical stability, low density and ease of handling of the fibres during concrete production are characteristics that could improve suitability for use in FRC.

Real structural applications have provided remarkable financial improvements, with use of PFRC being one of the materials of the future in the construction field. This study has outlined the standards that could arguably assist engineers in the reduction or total substitution of conventional reinforcement by PFRC.

Furthermore, this paper has also provided a review of the predictive tools available for assessing the orientation factor. The advantages that use of self-compacting concrete provides to fibre distribution and orientation have been assessed. The constitutive relations found might be implemented in structural design 
in order to achieve a reliable use of polyolefin-based fibres as reinforcement for concrete. It is possible to conclude that polyolefin fibre reinforced concrete is nowadays an outstanding alternative for certain structural applications. Some examples of uses of PFRC in civil engineering are tunnel linings, tunnel slabs, pipelines, foundations and some others $(23,32,43,114)$ Regarding construction costs it can be pointed out that the cost of a kilogram of polyolefin fibres is around two times the one of steel fibres. However, as the total amounts of fibres are noticeably lower than in the case of steel fibres there might be a direct economic saving in concrete manufacturing and production $(35,115)$. Besides, economic savings might not be only reflected in the construction costs but also in the maintenance and repairs where the use of polyolefin fibres when PFRC is applied in chemical hazardous environments is clearly more profitable.

Some considerations should be borne in mind when using PFRC. First of all, the reduced modulus of elasticity of the fibres is responsible for the load drop after reaching the peak load. This load drop is greater than the one that appear if steel fibres are used. Consequently, this matter should be taken into account when analysing the width of the cracks at SLS. In the case of ULS the use of polyolefin fibres, due to their contribution to residual stresses at high strain states, improve the robustness of the concrete element. Moreover, it is true that when using polyolefin fibres only one third of the weight of the steel fibres are required for reaching the same residual strengths. However, this amount of polyolefin fibres represent three times more volume than the correspondent amount of steel fibres. Thus, the influence that this greater volume of fibres might have in the fresh state properties should be contemplated. This case is of key importance when applying PFRC in congested areas of reinforced concrete.

\section{ACKNOWLEDGEMENTS}

The authors gratefully acknowledge the financial support provided by the Ministry of Economy, Industry and Competitiveness of Spain by means of the Research Fund Project BIA2016-78742-C22-R. In addition, the authors also acknowledge the support provided by the Industry-University Chairs "SIKA" and "Calle 30".

\section{REFERENCES}

1. Nawy, E. G. (2008). Concrete construction engineering handbook. 2ed. CRC press.

2. Romualdi, James P; Batson, G. B (1963) Behavior of reinforced concrete beams with closely spaced reinforcement. ACI J. Proc.. 60, 6. https://doi.org/10.14359/7878

3. Romualdi, James P.; Mandel, James A. (1964) Tensile Strength of concrete Affected by Unigormly Distributed and Closely Spaced Short Lengths of wire Reinforcement, ACI J. Proc 61(6), 1964. https://doi.org/10.14359/7801
4. ACI Committee 544, ACI 544.3R-08. Guide for specifying, proportioning, and production of fiber reinforced concrete, Farmington Hills: American Concrete Institute, 2008.

5. Fib Model Code, Paris: Fédération Internationale du Béton fib/International Federation for Structural Concrete, 2010.

6. RILEM TC-162-TDF Bending test: Final recommendations, 2002.

7. RILEM TC 162-TDF. (2000) Test and design methods for steel fibre reinforced concrete, Mat. Struct. 33[2], 33, 75-81. https://doi.org/10.1007/BF02484159

8. CNR-DT 204, 2006. Guide for the design and construction of fiber-reinforced concrete structures, Consiglio Nazionale delle Riserche, Roma.

9. EHE-08, Spanish Struct. Concrete. Code, Spanish Minister of Public Works, Madrid, 2008.

10. Ramakrishnan, V. (1999). Structural Application of Polyolefin Fiber Reinforced Concrete. Special Publication, $182,235-253$.

11. Serna, P.; Arango, S.; Ribeiro, T.; Núñez, A. M.; GarciaTaengua, E. (2009). Structural cast-in-place SFRC: technology, control criteria and recent applications in spain. Mat. Struct. 42, 1233-1246. https://doi.org/10.1617/s11527-009-9540-9

12. Serna, P. (2007). Recientes ejemplos estructurales de aplicación de hormigón de fibras. Avances en tecnología del hormigón en construcción subterránea, Jornada Técnica, 33-48.

13. EN 14889-1, Fibres for concrete. Steel fibres. Definitions, specifications and conformity, 2008.

14. EN 14889-2, Fibres for concrete. Polymer fibres. Definitions, specifications and conformity, 2008 .

15. EN 14845-1, Test methods for fibres in concrete. Part I: Reference concretes, 2006.

16. Di Prisco, M.; Colombo, M.; Dozio, D. (2013) Fibrereinforced concrete in fib Model Code 2010: principles, models and test validation, Struct. Concrete, 14[4], pp. 342-361, 2013. https://doi.org/10.1002/suco.201300021

17. Pujadas, P.; A. Blanco; Cavalaro, S. ;Aguado, A. (2014) Plastic fibres as the only reinforcement for flat suspended slabs: Experimental investigation and numerical simulation, Construc. Build. Mat. 57, 92-104. https://doi.org/10.1016/j. conbuildmat.2014.01.082

18. Bentur, A; Mindess, S. (2006) Fibre reinforced cementitious composites, Taylor \& Francis.

19. Yin, S; Tuladhar, R. Shi, F; Combe, M. Collister, T; Sivakugan, N. (2015). Use of macro plastic fibres in concrete: a review. Construc. Build. Mat., 93, 180-188. https:// doi.org/10.1016/j.conbuildmat.2015.05.105

20. Trottier, J. F.; Mahoney, M. (2001). Innovative synthetic fibers. Concrete International, 23[6], 23-28.

21. Alberti, M. G.; Enfedaque, A.; Gálvez, J. C. (2014). On the mechanical properties and fracture behavior of polyolefin fiber-reinforced self-compacting concrete. Construc. Build. Mat., 55, 274-288. https://doi.org/10.1016/j. conbuildmat.2014.01.024

22. Soutsos, M. N.; Le, T. T. ; Lampropoulos, A. P. (2012). Flexural performance of fibre reinforced concrete made with steel and synthetic fibres. Construc. Build. Mat., 36, 704-710. https://doi.org/10.1016/j. conbuildmat.2012.06.042

23. Behfarnia, K.; Behravan, A. (2014). Application of high performance polypropylene fibers in concrete lining of water tunnels. Mater. Design., 55, 274-279. https://doi. org/10.1016/j.matdes.2013.09.075

24. Kawashima, K.; Zafra, R.; Sasaki, T.; Kajiwara, K.; Nakayama, M. (2011). Effect of polypropylene fiber reinforced cement composite and steel fiber reinforced concrete for enhancing the seismic performance of bridge columns. J. Earthq. Engineer., 15[8], 1194-1211. https://doi.org/10.10 $80 / 13632469.2011 .569051$

25. Banthia, N.; Gupta, R. (2006). Influence of polypropylene fiber geometry on plastic shrinkage cracking in concrete. Cem. Concr. Res., 36[7], 1263-1267. https://doi.org/10.1016/j. cemconres.2006.01.010

26. Alberti, M. G.; Enfedaque, A.; Gálvez, J. C. (2016). Fracture mechanics of polyolefin fibre reinforced concrete: Study of the influence of the concrete properties, casting procedures, the fibre length and specimen size. Engineer. 
Fractu. Mech., 154, 225-244. 27. https://doi.org/10.1016/j. engfracmech.2015.12.032

27. Alberti, M. G.; Enfedaque, A.; Gálvez, J. C. (2015). Comparison between polyolefin fibre reinforced vibrated conventional concrete and self-compacting concrete. Construc. Build. Mat., 85, 182-194.

28. Pujadas, P.; Blanco, A.; Cavalaro, S.; de la Fuente, A.; Aguado, A. (2014). Fibre distribution in macro-plastic fibre reinforced concrete slab-panels. Construc. Build. Mat., 64, 496-503. https://doi.org/10.1016/j.conbuildmat.2014.04.067

29. Alberti, M. G.; Enfedaque, A.; Gálvez, J. C.; Agrawal, V. (2016). Fibre distribution and orientation of macrosynthetic polyolefin fibre reinforced concrete elements. Construc. Build. Mat., 122, 505-517. https://doi.org/10.1016/j. conbuildmat.2016.06.083

30. Alberti, M. G.; Enfedaque, A.; Gálvez, J. C.; Agrawal, V. (2016). Reliability of polyolefin fibre reinforced concrete beyond laboratory sizes and construction procedures. Compos. Struct., 140, 506-524. https://doi.org/10.1016/j. compstruct.2015.12.068

31. Alberti, M. G. (2015). Polyolefin fibre-reinforced concrete: from material behaviour to numerical and design considerations. Doctoral Thesis. Universidad Politécnica Madrid. http://oa.upm.es/36414/

32. Alberti, M. G.; Enfedaque, A.; Gálvez, J. C.; Pinillos, L. (2017). Structural Cast-in-Place Application of Polyolefin Fiber-Reinforced Concrete in a Water Pipeline Supporting Elements. J. Pipeline Syst. Eng., 8(4), 05017002. https://doi. org/10.1061/(ASCE)PS.1949-1204.0000274

33. Yin, S.; Tuladhar, R.; Sheehan, M.; Combe, M.; Collister, T. (2016). A life cycle assessment of recycled polypropylene fibre in concrete footpaths. J. Clean. Prod., 112, 2231-2242. https://doi.org/10.1016/j.jclepro.2015.09.073

34. Shen, L.; Worrell, E.; Patel, M. K. (2010). Open-loop recycling: A LCA case study of PET bottle-to-fibre recycling. Resour. Conser. Recy., 55[1], 34-52. https://doi.org/10.1016/j. resconrec.2010.06.014

35. Sorensen, C.; Berge, E.; Nikolaisen, E. B. (2014). Investigation of fiber distribution in concrete batches discharged from ready-mix truck. International J. Concr. Struct. Mater., 8[4], 279-287. https://doi.org/10.1007/ s40069-014-0083-2

36. Ochi, T.; Okubo, S.; Fukui, K. (2007). Development of recycled PET fiber and its application as concrete-reinforcing fiber. Cem. Concr. Comp., 29[6], 448-455. https://doi. org/10.1016/j.cemconcomp.2007.02.002

37. SUgbolue, S.C. (2009). Polyolefin fibres: industrial and medical applications., CRC Press, Cambridge.

38. McYintyre, J.E. (2004). Synthetic fibres: nylon, polyester, acrylic, polyolefin, Elsevier

39. Pujadas, P. (2013). Caracterización y diseño del homigón reforzado con fibras plásticas. Doctoral Thesis, Universitat Politècnica de Catalunya.

40. Alberti, M. G.; Enfedaque, A.; Gálvez, J. (2015). Improving the reinforcement of polyolefin fiber reinforced concrete for infrastructure applications. Fibers, 3[4], 504-522. https:// doi.org/10.3390/fib3040504

41. Alberti, M. G.; Enfedaque, A.; Gálvez, J.C. (2018). Polyolefin Fibres for the Reinforcement of Concrete, in Alkenes, InTech.

42. EN 14651:2007+Al [2007] Test method for metallic fibre concrete. Measuring the flexural tensile strength (limit of proportionality (LOP), residual)

43. Wimpenny, D; Angerer, W; Cooper, T; Bernard, S. (2009). The use of steel and synthetic fibres in concrete under extreme conditions. In $24^{\text {th }}$ Biennial Conference of the Concrete Institute of Australia, Sydney, Australia (Vol. 17).

44. Enfedaque, A.; Alberti, M. G.; Paredes, J. A.; Gálvez, J. C. (2017). Interface properties of polyolefin fibres embedded in self-compacting concrete with a bond improver admixture. Theor. Appl. Fract. Mec., 90, 287-293. https://doi. org/10.1016/j.tafmec.2017.06.015

45. Wang, Y.; Backer, S.; Li, V. C. (1987). An experimental study of synthetic fibre reinforced cementitious composites. J. Mater. S., 22[12], 4281-4291. https://doi.org/10.1007/BF01132019
46. Ramakrishnan, V.; Sivakumar, C. (1999). Performance of Polyolefin Fiber Reinforced Concrete Under Cyclic Loading. ACI Special Publication, 186, 161-182.

47. Mindess, S.; Wang, N.; Rich, L. D.; Morgan, D. R. (1998). Impact resistance of polyolefin fibre reinforced precast units. Cem. Concr. Comp., 20[5], 387-392. https://doi.org/10.1016/ S0958-9465(98)00016-X

48. Yan, L.; Jenkins, C. H. ; Pendleton, R. L. (2000). Polyolefin fiber-reinforced concrete composites: Part I. Damping and frequency characteristics. Cem. Concr. Res., 30[3], 391-401. https://doi.org/10.1016/S0008-8846(99)00267-7

49. Trottier, J. F.; Mahoney, M.; Forgeron, D. (2002). Can synthetic fibers replace welded-wire mesh in slabs-on-ground? Concr. Int., 24[11], 59-68.

50. Cengiz, O.; Turanli, L. (2004). Comparative evaluation of steel mesh, steel fibre and high-performance polypropylene fibre reinforced shotcrete in panel test. Cem. Concr. Res., 34[8], 1357-1364. https://doi.org/10.1016/j. cemconres.2003.12.024

51. Bernard, E. S. (2004). Durability of cracked fibre reinforced shotcrete. In Shotcrete: more engineering developments ( $\mathrm{pp}$. 69-76). CRC Press.

52. Alberti, M. G.; Enfedaque, A.; Gálvez, J. C. (2018). A review on the assessment and prediction of the orientation and distribution of fibres for concrete. Compos. Part B-Eng., 151, 274-290. https://doi.org/10.1016/j.compositesb.2018.05.040

53. EN 12350-8:2010, Testing fresh concrete. Part 8: Selfcompacting concrete. Slump-flow test, 2010.

54. EN 12350-9:2010, Testing fresh concrete. Part 9: Selfcompacting concrete. V-funnel test, 2010.

55. Grünewald, S. (2004). Performance-based design of selfcompacting fibre reinforced concrete. Delft University Press. Delft, The Netherlands.

56. EN 12390-3, "Testing hardened concrete. Part 3: Compressive strength of test specimens", 2009.

57. Boulekbache, B.; Hamrat, M.; Chemrouk, M.; Amziane, S. (2010). Flowability of fibre-reinforced concrete and its effect on the mechanical properties of the material. Construc. Build. Mat., 24[9], 1664-1671. https://doi.org/10.1016/j. conbuildmat.2010.02.025

58. Markeset, G. (1993). Failure of concrete under compressive strain gradients. Ph.D. Thesis, The Norwegian Institute of Technology, Trondheim.

59. EN 12390-6, Testing hardened concrete. Part 6. Tensile spliting strength of test specimens, 2009.

60. EN 12390-13, Testing hardened concrete - Part 13: Determination of secant modulus of elasticity in compression, 2013

61. Altun, F.; Haktanir, T.; Ari, K. (2007). Effects of steel fiber addition on mechanical properties of concrete and RC beams. Construc. Build. Mat., 21[3], 654-661. https://doi. org/10.1016/j.conbuildmat.2005.12.006

62. Thomas, J.; Ramaswamy, A. (2007). Mechanical properties of steel fiber-reinforced concrete. J. Mater Civil Eng., 19[5], 385-392. https://doi.org/10.1061/ (ASCE)0899-1561(2007)19:5(385)

63. Yan, L.; Pendleton, R. L.; Jenkins, C. H. M. (1998). Interface morphologies in polyolefin fiber reinforced concrete composites. Compo. Part A-Appl. S., 29[5-6], 643-650. https://doi.org/10.1016/S1359-835X(97)00114-0

64. Lerch, J. O.; Bester, H. L.; Van Rooyen, A. S.; Combrinck, R.; de Villiers, W. I.; Boshoff, W. P. (2018). The effect of mixing on the performance of macro synthetic fibre reinforced concrete. Cem. Concr. Res., 103, 130-139. https://doi. org/10.1016/j.cemconres.2017.10.010

65. Cunha, V. M.; Barros, J. A.; Sena-Cruz, J. (2007). Pullout behaviour of hooked-end steel fibres in self-compacting concrete. Universidade do Minho. Departamento de Engenharia Civil (DEC).

66. Laranjeira, F. ; Molins, C. ; Aguado, A. (2010). Predicting the pullout response of inclined hooked steel fibers. Cem. Concr. Res., 40[10], 1471-1487. https://doi.org/10.1016/j. cemconres.2010.05.005

67. Døssland, Å. L. (2008). Fibre reinforcement in load carrying concrete structures: laboratory and field investigations compared with theory and finite element 
analysis. Ph.D. thesis. Norwegian University of Science and Technology, Department of Structural Engineering.

68. Fantilli, A. P.; Vallini, P. (2007). A cohesive interface model for the pullout of inclined steel fibers in cementitious matrixes. J. Adv. Concr. Technol., 5[2], 247-258. https://doi. org/10.3151/jact.5.247

69. Alberti, M. G.; Enfedaque, A.; Gálvez, J. C.; Ferreras, A. (2016). Pull-out behaviour and interface critical parameters of polyolefin fibres embedded in mortar and self-compacting concrete matrixes. Construc. Build. Mat., 112, 607-622. https://doi.org/10.1016/j. conbuildmat.2016.02.128

70. Robins, P. ; Austin, S. ; Jones, P. (2002). Pull-out behaviour of hooked steel fibres. Materials and structures, 35[7], 434 442. https://doi.org/10.1007/BF02483148

71. ASTM C 1609/C 1690M-07, Standard test method for flexural performance of fiber reinforced concrete (using beam with third-point loading), 2007.

72. Vandewalle, L.; Heirman, G.; Van Rickstal, F. (2008) Fibre orientation in self-compacting fibre reinforced concrete, in Proc. of the 7th Int. RILEM Symp. on Fibre Reinforced Concrete: Design and Applications (BEFIB2008)

73. Krenchel, H. (1978). Fibre spacing and specific fibre surface, in Testing and Test Methods of Fibre Cement Composites, Proceedings of the RILEM Symposium, 1978 (Construction Press Ltd., Lancaster 1978) 69-79.

74. Dupont, D.; Vandewalle, L. (2005). Distribution of steel fibres in rectangular sections. Cem. Concr. Comp., 27[3], 391-398. https://doi.org/10.1016/j.cemconcomp.2004. 03.005

75. Alberti, M. G.; Enfedaque, A.; Gálvez, J. C. (2017). On the prediction of the orientation factor and fibre distribution of steel and macro-synthetic fibres for fibre-reinforced concrete. Cem. Concr. Comp., 77, 29-48. https://doi. org/10.1016/j.cemconcomp.2016.11.008

76. Soroushian, P.; Lee, C. D. (1990). Distribution and orientation of fibers in steel fiber reinforced concrete. Mater. J., 87[5], 433-439. https://doi.org/10.14359/1803

77. Lee, C.; Kim, H. (2010). Orientation factor and number of fibers at failure plane in ring-type steel fiber reinforced concrete. Cem. Concr. Res., 40[5], 810-819. https://doi. org/10.1016/j.cemconres.2009.11.009

78. Laranjeira, F.; Aguado, A.; Molins, C.; Grünewald, S.; Walraven, J.; Cavalaro, S. (2012). Framework to predict the orientation of fibers in FRC: a novel philosophy. Cem. Concr. Res., 42[6], 752-768. https://doi.org/10.1016/j. cemconres.2012.02.013

79. Rao, C. K. (1979); Effectiveness of random fibres in composites. Cem. Concr. Res., 9[6], 685-693. https://doi. org/10.1016/0008-8846(79)90063-2

80. Giaccio, G.; Tobes, J. M.; Zerbino, R. (2008). Use of small beams to obtain design parameters of fibre reinforced concrete. Cem. Concr. Comp., 30[4], 297-306. https://doi. org/10.1016/j.cemconcomp.2007.10.004

81. Alberti, M. G.; Enfedaque, A.; Gálvez, J. C.; Cánovas, M. F. Osorio, I. R. (2014). Polyolefin fiber-reinforced concrete enhanced with steel-hooked fibers in low proportions. Mater. Design., 60, 57-65. https://doi.org/10.1016/j. matdes.2014.03.050

82. Zerbino, R.; Tobes, J. M.; Bossio, M. E.; Giaccio, G. (2012). On the orientation of fibres in structural members fabricated with self compacting fibre reinforced concrete. Cem. Concr. Comp., 34[2], 191-200. https://doi.org/10.1016/j. cemconcomp.2011.09.005

83. Torrijos, M. C.; Barragán, B. E.; Zerbino, R. L. (2010). Placing conditions, mesostructural characteristics and postcracking response of fibre reinforced self-compacting concretes. Construc. Build. Mat., 24[6], 1078-1085. https://doi. org/10.1016/j.conbuildmat.2009.11.008

84. Alani, A. M.; Beckett, D. (2013). Mechanical properties of a large scale synthetic fibre reinforced concrete ground slab. Construc. Build. Mat., 41, 335-344. https://doi.org/10.1016/j. conbuildmat.2012.11.043

85. Blanco, A.; Pujadas, P.; De la Fuente, A.; Cavalaro, S.; Aguado, A. (2013). Application of constitutive models in
European codes to RC-FRC. Construc. Build. Mat., 40, 246-259. https://doi.org/10.1016/j.conbuildmat.2012.09.096

86. Yang, J. M.; Min, K. H.; Shin, H. O.; Yoon, Y. S. (2012). Effect of steel and synthetic fibers on flexural behavior of high-strength concrete beams reinforced with FRP bars. Compos. Part B-Eng., 43[3], 1077-1086. https://doi. org/10.1016/j.compositesb.2012.01.044

87. Yin, S.; Tuladhar, R.; Collister, T.; Combe, M.; Sivakugan, N.; Deng, Z. (2015). Post-cracking performance of recycled polypropylene fibre in concrete. Construc. Build. Mat., 101, 1069 1077. https://doi.org/10.1016/j.conbuildmat.2015.10.056

88. Buratti, N.; Mazzotti, C.; Savoia, M. (2011). Post-cracking behaviour of steel and macro-synthetic fibre-reinforced concretes. Construc. Build. Mat., 25[5], 2713-2722. https:// doi.org/10.1016/j.conbuildmat.2010.12.022

89. Erdem, S:-Dawson, A. R - Thom, N.H. (2011) Microstructurelinked strength properties and impact response of conventional and recycled concrete reinforced with steel and synthetic macro fibres. Construc. Build. Mat. 25[10], 4025-4036. https:// doi.org/10.1016/j.conbuildmat.2011.04.037

90. Bencardino, F.; Rizzuti, L.; Spadea, G.; Swamy, R. N. (2010). Experimental evaluation of fiber reinforced concrete fracture properties. Compos. Part B-Eng., 41[1], 17-24. https://doi.org/10.1016/j.compositesb.2009.09.002

91. Alberti, M.G.; Enfedaque, A.; Gálvez, J. C. (2016). Polyolefinbased fibres and combination with steel fibres: seeking a more sustainable Struct. Concrete.. In II International Conference on Concrete Sustainability ICCS16, Madrid.

92. DBV, Technologie des Stahlfaser-betons und Stahlfaserprit, 1992.

93. DBV, Merkblatt StahlfaserbetonDeutsche Beton Vereins, 2001.

94. European Committee for Standardization (2004). "Eurocode 2: design of concrete structures-part 1-1: general rules and rules for buildings".

95. Hillerborg, A.; Modéer, M.; Petersson, P. E. (1976). Analysis of crack formation and crack growth in concrete by means of fracture mechanics and finite elements. Cem. Concr. Res., 6[6], 773-781. https://doi.org/10.1016/0008-8846(76)90007-7

96. de Montaignac, R.; Massicotte, B; Charron, J. P. (2012). Design of SFRC structural elements: flexural behaviour prediction. Mater. Struc., 45[4], 623-636. https://doi. org/10.1617/s11527-011-9785-y

97. Ulfkjær, J. P; Krenk, S.; Brincker, R. (1995). Analytical model for fictitious crack propagation in concrete beams. J. Eng. Mech., 121[1], 7-15. https://doi.org/10.1061/ (ASCE)0733-9399(1995)121:1(7)

98. Massicotte, B. (2004). Implementing SFRC design into North American codes: application to a building floor. Invited paper to the International workshop on the advanced in fibre reinforced concrete, Bergamo, Italia, September (pp. 24-25).

99. AFGC-SETRA, Ultra high performance fibre-reinforced concretes, interim recommendations, 2002.

100. Alberti, M.G.; Enfedaque, A.; Gálvez, J. C.; Reyes, E. (2017). Numerical modelling of the fracture of polyolefin fibre reinforced concrete by using a cohesive fracture approach. Compos. Part B-Eng., 111, 200-210. https://doi. org/10.1016/j.compositesb.2016.11.052

101. Li, V. C.; Ward, R.; Hamza, A. M. (1992). Steel and synthetic fibers as shear reinforcement. ACI Mat. J., vol. 89[5], 499-508. https://doi.org/10.14359/1822

102. Barragán, B. (2002). Failure and toughness of steel fiber reinforced concrete under tension and shear, Doctoral Thesis: Universitat Politècnica de Catalunya.

103. Voo, Y. L.; Poon, W. K.; Foster, S. J. (2010). Shear strength of steel fiber-reinforced ultrahigh-performance concrete beams without stirrups. J. Struct. Eng. 136[11], 1393-1400. https://doi.org/10.1061/(ASCE)ST.1943-541X.0000234

104. Cuenca, E.; Serna, P. (2010). Shear behavior of SelfCompacting concrete and Fiber-Reinforced concrete push-off specimens. Design, Production and Placement of Self-Consolidating Concrete (pp. 429-438). Springer, Dordrecht. https://doi.org/10.1007/978-90-481-9664-7 36

105. Jongvivatsakul, P.; Attachaiyawuth, A.; Pansuk, W. (2016). A crack-shear slip model of high-strength steel 
fiber-reinforced concrete based on a push-off test. Construc. Build. Mat., 126, 924-935. https://doi.org/10.1016/j. conbuildmat.2016.09.080

106. Echegaray, J. (2014). Upgrading the push-off test to analyse the contribution of steel fibre on shear. $\mathrm{PhD}$ thesis, Universidad Politécnica de Valencia.

107. Picazo, A.; Gálvez, J. C.; Alberti, M. G.; Enfedaque, A. (2018). Assessment of the shear behaviour of polyolefin fibre reinforced concrete and verification by means of digital image correlation. Construc. Build. Mat., 181, 565-578. https://doi.org/10.1016/j.conbuildmat.2018.05.235

108. Serna Ros, P.; Martí Vargas; J. R., Bossio, M. E.; Zerbino, R. (2016). Creep and residual properties of cracked macrosynthetic fibre reinforced concretes. Mag. Concrete. Res., 68[4], 197-207. https://doi.org/10.1680/macr.15.00111

109. Kurtz, S.; Balaguru, P. (2000). Postcrack creep of polymeric fiber-reinforced concrete in flexure. Cem. Concr. Res., 30[2], 183-190. https://doi.org/10.1016/S0008-8846(99)00228-8

110. Bernard, E. S. (Ed.). (2004). Shotcrete: More Engineering Developments: Proceedings of the Second International Conference on Engineering Developments in Shotcrete, October 2004, Cairns, Queensland, Australia. Taylor \& Francis.

111. Bernard, E. S. (2010). Influence of Fiber Type on Creep Deformation of Cracked Fiber-Reinforced Shotcrete
Panels. ACI Mat. J., 107[5], 474-480. https://doi. org/10.14359/51663967.

112. Boulekbache, B.; Hamrat, M.; Chemrouk, M.; Amziane, S. (2016). Flexural behaviour of steel fibrereinforced concrete under cyclic loading. Construc. Build. Mat., 126, 253-262. https://doi.org/10.1016/j. conbuildmat.2016.09.035

113. Goel, S.; Singh, S. P.; Singh, P. (2012). Flexural fatigue strength and failure probability of self compacting fibre reinforced concrete beams. Eng. Struct., 40, 131-140. https://doi.org/10.1016/j.engstruct.2012.02.035

114. Alberti, M. G.; Gálvez, J. C.; Enfedaque, A.; Carmona, A. Valverde, C.; Pardo, G. (2018). Use of Steel and Polyolefin Fibres in the La Canda Tunnels: Applying MIVES for Assessing Sustainability Evaluation. Sustainability, 10[12], 4765. https://doi.org/10.3390/su10124765

115. Enfedaque, A.; Alberti, M.G.; Gálvez, J.C.; Rivera, M.; Simón-Talero, J. (2018). Can Polyolefin Fibre Reinforced Concrete Improve the Sustainability of a Flyover Bridge? Sustainability, 10[12], 4583. https://doi.org/10.3390/ su10124583

116. EN 12350-8:2010. Testing fresh concrete. Part 8: Selfcompacting concrete. Slump-flow test; 2010.

117. EN 12350-9:2010. In testing fresh concrete. Part 9: Selfcompacting concrete. V-funnel test; 2010 . 